\title{
Effect of the Atlantic Meridional Overturning Circulation on
} Atmospheric $\mathrm{pCO}_{2}$ Variations

\author{
Amber Boot ${ }^{1}$, Anna S. Von Der Heydt ${ }^{1,2}$, and Henk A. Dijkstra ${ }^{1,2}$ \\ ${ }^{1}$ Institute for Marine and Atmospheric research Utrecht, Department of Physics, Utrecht University, Utrecht, the Netherlands \\ ${ }^{2}$ Center for Complex Systems Studies, Utrecht University, Utrecht, the Netherlands
}

Correspondence: A. Boot<d.boot@uu.nl>

\begin{abstract}
Proxy records show large variability of atmospheric $\mathrm{pCO}_{2}$ on different time scales. Most often such variations are attributed to a forced response of the carbon cycle to changes in external conditions. Here, we address the problem of internally generated variations in $\mathrm{pCO}_{2}$ due to pure carbon-cycle dynamics. We focus on the effect of the strength of Atlantic Meridional Overturning Circulation (AMOC) on such internal variability. Using the Simple Carbon Project Model v1.0 (SCP-M), which we

5 have extended to represent a suite of nonlinear carbon-cycle feedbacks, we efficiently explore the multi-dimensional parameter space to address the $\mathrm{AMOC}-\mathrm{pCO}_{2}$ relationship. We find that climatic boundary conditions, and the representation of biological production in the model are most important for this relationship. When climate sensitivity in our model is increased, we find intrinsic oscillations due to Hopf bifurcations with multi-millennial periods. The mechanism behind these oscillations is clarified and related to the coupling of atmospheric $\mathrm{pCO}_{2}$ and the alkalinity cycle, via the river influx and the sediment outflux.
\end{abstract} This mechanism is thought to be relevant for explaining atmospheric $\mathrm{pCO}_{2}$ variability during glacial cycles.

\section{Introduction}

Atmospheric $\mathrm{pCO}_{2}$ values show large variations on many different time scales. Over the Cenozoic, $\mathrm{pCO}_{2}$ values have gradually decreased from values of up to 2,500 ppmv in the Eocene to $300 \mathrm{ppmv}$ at the end of the Pliocene. When considering the Pleistocene glacial-interglacial cycles, one of the remarkable results is the strong correlation between $\mathrm{pCO}_{2}$ and temperature, with dominant variations of about 100 ppmv in 100,000 years, as reconstructed from ice cores (Petit et al., 1999). Over the industrial period, $\mathrm{pCO}_{2}$ values have increased by 130 ppmv due to human activities (Friedlingstein et al., 2020). This forced trend is superposed on natural variability associated with the seasonal cycle and longer time scale climate variability (Gruber et al., 2019). The effect of the natural variability is much lower than the forced trend on such relatively short time scales. For example, the El Niño- Southern Oscillation (ENSO), a dominant mode of interannual climate variability, induces atmospheric $\mathrm{pCO}_{2}$ variations of only 1-2 ppmv (Jiang and Yung, 2019). Most studies seek to explain such variations in $\mathrm{pCO}_{2}$ as a forced response of the carbon cycle to changes in external conditions. For example, glacial cycles are thought to be caused by orbital variations in insolation, possibly amplified by physical processes in the climate system (Muller and MacDonald, 2000). Such variations in temperature (and other quantities, e.g., precipitation) then affect the carbon cycle, leading to changes in $\mathrm{pCO}_{2}$. On the other hand, changes in $\mathrm{pCO}_{2}$ will affect global mean temperature and hence may amplify any temperature anomaly. Hence 
it is questionable whether the $\mathrm{pCO}_{2}$ response to orbital insolation changes can be considered as a solely forced response, with no internal dynamics of the carbon being involved (Rothman, 2015).

The carbon cycle is comprised of an extremely complex entangled set of processes which act in the different components of the climate system (e.g., land, ocean) on many different time scales. The marine carbon cycle, with its three main carbon pumps is a major player in this cycle, at present-day resulting in the uptake of about $25 \%$ of the human released emissions (Sabine et al., 2004). The carbon pumps involve physical processes, biological processes and processes in ocean sediments. Many carbon cycle feedbacks exist, either between only physical quantities or between biological and physical quantities. An example of such a feedback is the solubility feedback: for higher atmospheric $\mathrm{pCO}_{2}$, solubility of $\mathrm{CO}_{2}$ decreases due to higher ocean temperatures, resulting in relatively less $\mathrm{CO}_{2}$ uptake by the ocean and thus relatively higher atmospheric $\mathrm{pCO}_{2}$. Given this strongly nonlinear system, it would be strange if it would not show strong internal variability, i.e. variability which would exist even if the carbon-cycle system would be driven by a time-independent external forcing. There are indeed examples (Rothman, 2019), where oscillatory behavior in the carbon cycle has been attributed to internal carbon-cycle dynamics.

The physical context of all carbon pumps is the three-dimensional ocean circulation, which can be roughly decomposed in a wind-driven and an overturning component, the latter strongly related to the deep-ocean circulation. The Atlantic Meridional Overturning Circulation (AMOC) is a major component of the global overturning circulation because of its associated meridional transport of heat, salt and nutrients.

The relation between the $\mathrm{AMOC}$ and atmospheric $\mathrm{pCO}_{2}$ is not yet well understood. A direct effect of a changing $\mathrm{AMOC}$ is a change in the distribution of tracers such as temperature, dissolved inorganic carbon (DIC), alkalinity (Alk) and nutrients. For example, after an AMOC weakening the distributions of these tracers affect biological export production via reduced nutrient upwelling (Marchal et al., 1998; Menviel et al., 2008; Mariotti et al., 2012; Nielsen et al., 2019), and gas exchange via changing solubility of $\mathrm{CO}_{2}$ in the ocean (Menviel et al., 2014). Besides these direct effects, the AMOC also influences mixing in the Southern Ocean. Changes in this mixing due to a weaker AMOC can result in a higher outgoing flux of carbon to the atmosphere (e.g. Schmittner et al., 2007; Huiskamp and Meissner, 2012; Menviel et al., 2014). These processes form a complex puzzle where the sign of atmospheric $\mathrm{pCO}_{2}$ change following an $\mathrm{AMOC}$ strength change is difficult to determine. Currently, different models produce different results with respect to the sign of the atmospheric $\mathrm{pCO}_{2}$ change, which can be attributed to the assessed time scale, model used, and what climatic boundary conditions are used (Gottschalk et al., 2019).

On the other hand, $\mathrm{pCO}_{2}$ also influences the AMOC (Toggweiler and Russell, 2008) and present-day climate models forced with anthropogenic emissions, simulate a weaker AMOC for larger atmospheric $\mathrm{pCO}_{2}$ (Gregory et al., 2005; Weijer et al., 2020). By contrast, proxy data suggest that in the Last Glacial Maximum both atmospheric $\mathrm{pCO}_{2}$ and the strength of the AMOC were lower (Duplessy et al., 1988). This shows that there is also a sensitivity to climatic boundary conditions in the relation (Zhu et al., 2015) between the AMOC and atmospheric $\mathrm{pCO}_{2}$. The AMOC can also display tipping behavior (Weijer et al., 2019) under an increase of $\mathrm{pCO}_{2}$, which can have large effects on climate. Examples of these effects are disrupted heat transport (Ganachaud and Wunsch, 2000), changing precipitation patterns (Vellinga and Wood, 2002) and a different distribution of important tracers in the ocean. Such tipping can hence have strong consequences on the carbon cycle, and hence on atmospheric $\mathrm{pCO}_{2}$. 

using the Simple Carbon Project Model v1.0 (SCP-M). This model (O’Neill et al., 2019) simulates the most important carbon cycle processes in a simple global ocean box structure. The simple box setup enables us to efficiently scan the parameter space of the carbon-cycle model using parameter continuation methods. With this approach we aim answering the following three questions: (i) How does atmospheric $\mathrm{pCO}_{2}$ respond to changes in the strength of a constant (in time) AMOC? (ii) Does the $\mathrm{pCO}_{2}$-AMOC feedback lead to new variability phenomena? And (iii), are there tipping points and internal oscillations in the carbon cycle?

When answering these questions, we pay special attention to different (non-linear) carbon cycle feedbacks. We will also use two different model configurations to take account of different climatic boundary conditions, the pre-industrial (PI) configuration and the Last Glacial Maximum (LGM) configuration. The SCP-M, its configurations, the different additional feedbacks implemented, and the parameter continuation approach are described in Section 2. In Section 3 we present the results of the different cases considered, and we conclude the paper with a summary and discussion in Section 4.

\section{Methods}

\subsection{SCP-M}

The SCP-M is a carbon cycle box model focused on the marine carbon cycle. Because of its simple structure, it is well suited to test high level concepts in both modern and past configurations. In the ocean several tracers are resolved. In this study we will only use the three most important tracers: DIC, Alk, and phosphate $\left(\mathrm{PO}_{4}^{3-}\right)$, to reduce the problem size. In the original model there is also a terrestrial biosphere component, and several sources of $\mathrm{CO}_{2}$ to the atmosphere. We will not use these, since our focus is on the marine carbon cycle. The processes which are resolved are ocean overturning circulation, sea-air gas exchange, biological production, calcium carbonate $\left(\mathrm{CaCO}_{3}\right)$ production and dissolution, and river and sediment fluxes.

The model consists of 8 boxes: 1 atmospheric box and 7 oceanic boxes (Fig. 1). This means that the sediment stock is not explicitly solved for in the model. In the model, the ocean boxes are differentiated on latitude and depth. Consequently, there is no longitudinal variation, and no differentiation between ocean basins. The used boxes are: (1) a low-latitude surface box, (2) a northern high latitude surface box, (3) an intermediate ocean box, (4) a deep ocean box, (5) a southern high latitude surface box, (6) an abyssal ocean box, and (7) a sub-polar surface box. This division in the ocean is based on regions in the ocean where the water masses have similar characteristics. The different boxes are connected via ocean circulation and mixing, which is based upon a conceptual view of the ocean circulation (Talley, 2013). The largest circulation is the Global Overturning Circulation (GOC; $\psi_{1}$ ). This circulation connects boxes 4-7 and represents the formation of Antarctic Bottom Water. Next to the GOC, the other major circulation is the AMOC $\left(\psi_{2}\right)$ which connects boxes 2-4 and 7. Lastly, there is bidirectional (vertical) mixing between boxes 4 and $6\left(\gamma_{1}\right)$ and boxes 1 and $3\left(\gamma_{2}\right)$.

To be able to solve for several fluxes, such as the air-sea gas exchange, the $\mathrm{pH}$ in the ocean needs to be determined. Unfortunately, $\mathrm{pH}$ is not a conservative tracer, which means that we need a carbonate chemistry module to solve for $\mathrm{pH}$. In the SCP-M, a direct solver is used where the $\mathrm{pH}$ value of the previous time step is used as an estimate for the new step (Follows 


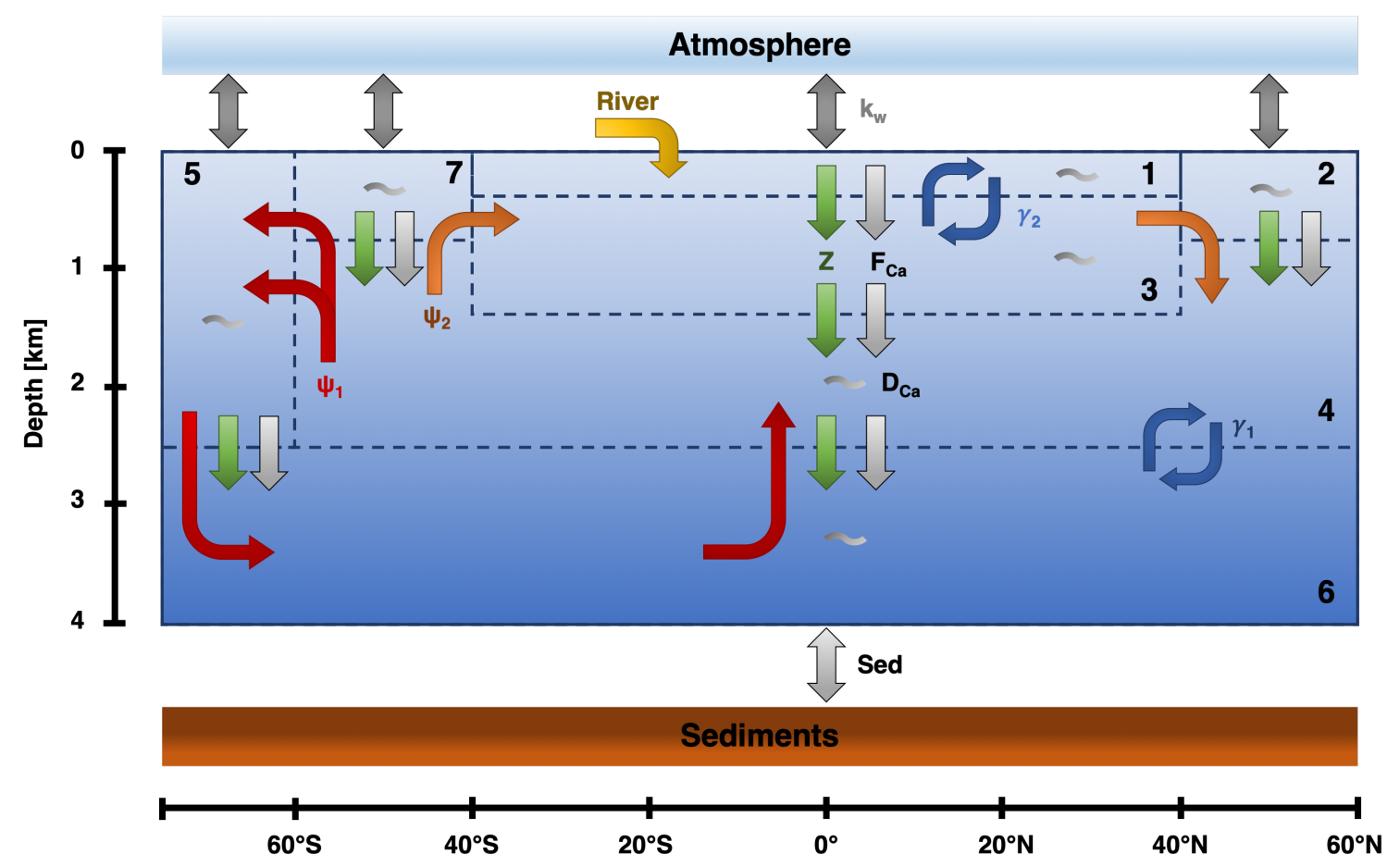

Figure 1. The box structure and fluxes for the SCP-M based on O'Neill et al. (2019). $\psi_{1}$ (red) is the GOC, $\psi_{2}$ (orange) is the AMOC, $\gamma_{1}$ and $\gamma_{2}$ (blue) represent bidirectional mixing. Biological fluxes are represented by the green arrows, calcifier fluxes by the light gray arrows, and general dissolution of calcium carbonate by the grey wiggles in the boxes. $k_{w}$ (gray) represents the gas exchange between the ocean and the atmosphere. Lastly, there is an influx in Box 1 via the rivers (yellow), and an outflux to the sediments (light gray).

et al., 2006). Using this carbonate chemistry, the model is able to determine the carbonate $\left(\mathrm{CO}_{3}^{2-}\right)$ concentration and oceanic $\mathrm{pCO}_{2}$. This latter quantity is used to model the exchange of $\mathrm{CO}_{2}$ between the atmosphere and ocean. For each surface box, the flux is proportional to the $\mathrm{pCO}_{2}$ difference between atmosphere and ocean, and a constant piston velocity $\left(k_{w}\right)$.

Biological production is constant in the SCP-M. Per surface box, a constant value is used to denote the biological export production at $100 \mathrm{~m}$ depth. The organic flux is remineralized in the subsurface boxes following the power law of Martin et al. (1987). The biological export production is also important for the carbonate pump. Via a constant rain ratio, the biological production is linked to the production of calcifiers. Besides organic growth via photosynthesis, calcifiers also take up DIC and Alk to form shells $\left(\mathrm{CaCO}_{3}\right)$. Upon death, these calcifiers sink to deeper boxes where the shells are dissolved. The dissolution of the shells is dependent on a constant dissolution and a saturation dependent solution. If the total dissolution of $\mathrm{CaCO}_{3}$ in the ocean is smaller (larger) than the production in the surface ocean, there is an outflux (influx) of DIC and Alk to (from) the sediments. The river flux for $\mathrm{PO}_{4}^{3-}$ is constant in the SCP-M and balanced by a constant outflux into the sediments. Influx of DIC and Alk via the rivers is variable and related to constant silicate and variable silicate and carbonate weathering. Here the 
Table 1. The parameter values that are different between the two configurations (PI and LGM). In columns 1 and 2 the parameter symbol and description are given. In column 3 the PI value is given and in column 4 the LGM value.

\begin{tabular}{|llcc|}
\hline Parameter & & PI-value & LGM-value \\
\hline$T_{1}$ & Temperature box 1 & 23.44 & 17.34 \\
$T_{2}$ & Temperature box 2 & 9.1 & 3.1 \\
$T_{7}$ & Temperature box 7 & 5.83 & 0.33 \\
$S_{1}$ & Salinity box 1 & $35.25 \mathrm{psu}$ & $36.25 \mathrm{psu}$ \\
$S_{2}$ & Salinity box 2 & $34.27 \mathrm{psu}$ & $35.27 \mathrm{psu}$ \\
$S_{5}$ & Salinity box 5 & $34.34 \mathrm{psu}$ & $35.34 \mathrm{psu}$ \\
$S_{7}$ & Salinity box 7 & $34.17 \mathrm{psu}$ & $35.17 \mathrm{psu}$ \\
$\gamma_{1}$ & Mixing deep - abyssal ocean & $29 \mathrm{~Sv}$ & $31 \mathrm{~Sv}$ \\
$\psi_{1}$ & General Overturning Circulation & $29 \mathrm{~Sv}$ & $18 \mathrm{~Sv}$ \\
$\psi_{2}$ & AMOC & $19 \mathrm{~Sv}$ & $15 \mathrm{~Sv}$ \\
$V_{n}$ & Volume box n & $1 \times V_{n}$ & $0.97 \times V_{n}$ \\
$A_{n}$ & Surface area box n & $1 \times S_{n}$ & $0.97 \times S_{n}$ \\
$k_{w_{5}}$ & Piston velocity box 5 & $3 \mathrm{~m} / \mathrm{day}$ & $1 \mathrm{~m} / \mathrm{day}$ \\
$p C O_{2, \text { base }}$ & Base atmospheric pCO & $244 \mathrm{ppm}$ & $145 \mathrm{ppm}$ \\
\hline
\end{tabular}

variable component is related to atmospheric $\mathrm{pCO}_{2}$. The difference between the influx of DIC and Alk and the outflux into the sediments determines the change in total carbon and Alk in the system.

A big advantage of the SCP-M is that it has two configurations: a PI configuration, and an LGM configuration. The parameter values in both configurations have been determined via extensive tuning of the model to observations and proxies in O'Neill et al. (2019). The configurations are differentiated on surface ocean temperature and salinity, ocean circulation, sea-ice cover in box 5, and total volume of the ocean. The parameter values of the two different SCP-M configurations can be found in Table 1.

\subsection{Representation of Carbon-Cycle Processes and Feedbacks}

The carbon cycle has many (non-linear) feedbacks which are not represented in the original SCP-M version to keep the model as simple as possible. The absence of these feedbacks can lead to non-physical behavior (e.g. negative concentrations) when parameter values, such as the AMOC strength, are changed. We have implemented several additional feedbacks which can be divided into two categories: those that mostly concern physical processes and those associated with biological processes. The feedbacks are included through parameters $\lambda$ 's; when such a parameter is zero, the feedback is not active in the SCP-M and the original version applies. For all feedbacks, except the feedback on the rain ratio (Eq. 9 below), the sign of the feedback is unclear beforehand as multiple (carbon cycle) processes are involved. 


\subsubsection{Physical processes}

An important feedback is the coupling of temperature to atmospheric $\mathrm{pCO}_{2}$. There are several ways temperature effects the carbon cycle. For example, decreasing temperatures increase the solubility of $\mathrm{CO}_{2}$, which results in more uptake of $\mathrm{CO}_{2}$ by the ocean. For this feedback, we make a distinction between box 5 and boxes 1, 2 and 7. Box 5, the southern high latitude surface box, is more isolated than the other boxes due to the Antarctic Circumpolar Circulation (ACC). Therefore, we have included the option in the model to use a different sensitivity in Box 5. The temperature in the boxes is calculated as follows

$T_{i}=T_{i, \text { base }}+\Delta T_{i}, \quad i=1,2,5,7$

$\Delta T_{i}=\lambda_{T} \times 0.54 \times 5.35 \times \ln \frac{C O_{2}}{C O_{2_{\text {base }}}}, \quad i=1,2,7$

$\Delta T_{5}=\lambda_{T 5} \times 0.54 \times 5.35 \times \ln \frac{C O_{2}}{C_{2}}$

Here $\mathrm{T}_{i, \text { base }}$ is the base temperature in the SCP-M. The change in temperature is dependent on atmospheric $\mathrm{pCO}_{2}$ and a base value of atmospheric $\mathrm{pCO}_{2}$. This base value is the steady state solution in the SCP-M without feedback (Table 1). Climate sensitivity can be changed via the $\lambda$ parameters. For a $\lambda$ of 1 , sea surface temperatures increase $2 \mathrm{~K}$ per $\mathrm{CO}_{2}$ doubling. As a reference, a $2 \mathrm{~K}$ warming for surface air temperatures is at the lower end of the range found in CMIP6 models (Zelinka et al., 2020).

Besides an effect on solubility, temperature can also affect the piston velocity. In the often used Wanninkhof (1992) formulation, the piston velocity is dependent on temperature via the Schmidt number (equations 4 and 5). In our model, we use this dependency on the Schmidt number, which causes the piston velocity to increase for warmer temperatures. Hence

$k_{w, i}=\left(1-\lambda_{P}\right) \times k_{w, i b a s e}+\lambda_{P} \times k_{w, i b a s e} \times\left(\frac{S c_{i}}{660}\right)^{-0.5}, \quad i=1,2,5,7$

140 Where

$S c_{i}=2116.8-136.25 T_{i}+4.7353 T_{i}^{2}-0.092307 T_{i}^{3}+0.0007555 T_{i}^{4}, \quad i=1,2,5,7$

In these equations, $k_{w}$ is the used piston velocity, $k_{w}$,base is the piston velocity in the SCP-M ( $\left.3 \mathrm{~m} / \mathrm{day}\right)$, and T is the temperature of the box in ${ }^{\circ} \mathrm{C}$. The $\lambda$ parameter needs to be either 0 (constant piston velocity, as in SCP-M) or 1 (variable piston velocity). Notice that if the temperature feedback is used $\left(\lambda_{T}>0\right)$, the Schmidt number depends on atmospheric $\mathrm{pCO}_{2}$.

\subsubsection{Biological processes}

A large limitation in the original SCP-M is the constant biological production. Nutrient availability introduces a large constraint on biological production but this process is completely absent in the original SCP-M. This process is introduced in the model 
here by adopting the expression used in the Long-term Ocean-atmosphere-Sediment Carbon cycle Reservoir model (LOSCAR) (Zeebe, 2012). In LOSCAR, production is dependent on the upwelling of nutrients, which in our model translates to the expressions

$$
\begin{aligned}
& Z_{1}=\left(1-\lambda_{B I}\right) \times Z_{1, \text { base }}+\lambda_{B I} \times\left(\gamma_{2} \times\left[P O_{4}^{3-}\right]_{3}+R_{P O 4}\right) \times \epsilon_{1} \\
& Z_{2}=\left(1-\lambda_{B I}\right) \times Z_{2, \text { base }}+\lambda_{B I} \times \psi_{2} \times\left[P O_{4}^{3-}\right]_{3} \times \epsilon_{2} \\
& Z_{5}=\left(1-\lambda_{B I}\right) \times Z_{5, \text { base }}+\lambda_{B I} \times \alpha \times\left[P O_{4}^{3-}\right]_{7} \times \epsilon_{5} \\
& Z_{7}=\left(1-\lambda_{B I}\right) \times Z_{7, \text { base }}+\lambda_{B I} \times\left(\alpha \times \psi_{1}+\psi_{2}\right) \times\left[P_{4}^{3-}\right]_{4} \times \epsilon_{7}
\end{aligned}
$$

In these equations $Z$ represents the production in the surface box, and $Z_{b a s e}$ the value used in the original SCP-M. Furthermore, $\alpha$ is the fraction of $\psi_{1}$ that moves from Box 4 to Box 7, and $\epsilon$ is the biological efficiency in the box. As with the piston velocity, $\lambda_{B I}$ is either 0 (SCP-M) or 1 . Notice that the current branch represented by $\psi_{1}$ which flows from Box 4 to Box 5 , does not influence the production in Box 5. We do not use this branch, since it is assumed to flow into Box 5 below the euphotic zone.

In the equations (6) also the biological efficiency $(\epsilon)$ is introduced. There are studies (e.g. Cael et al., 2017) where they relate biological efficiency to temperature. We have adopted a simple linear relation to represent the influence of temperature on biological efficiency, i.e.,

$\epsilon_{i}=\lambda_{\epsilon} \times\left(-0.1 \Delta T_{i}\right)+\epsilon_{i, b a s e}, \quad i=1,2,5,7$

In this equation, $\lambda_{\epsilon}$ controls how strong the relation is between the efficiency and temperature change $(\Delta T)$. In addition, $\epsilon_{b a s e}$ is the base value of the biological efficiency. These values have been fitted so that $Z$ is equal to $Z_{b a s e}$ under the original parameter values in the SCP-M.

In the SCP-M, $\mathrm{PO}_{4}^{3-}$ is the only nutrient. In the real ocean, additional nutrients play a role in biological production, one of them being nitrate $\left(\mathrm{NO}_{3}^{-}\right)$. During photosynthesis, organisms take up nitrate, and thereby increase Alk. This biological influence on Alk is not incorporated in the SCP-M, but present in many other models (e.g. Kwon and Primeau, 2008). We have included this influence as follows:

$A_{B i o, i}=\lambda_{B A} \times\left(-\frac{16}{106}\right) \times C_{B i o, i}, \quad i=1,2,3,4,5,6,7$

In this equation $\mathrm{A}_{B i o}$ is the biological flux affecting Alk. This flux is related to the DIC biological flux $\left(\mathrm{C}_{B i o}\right)$ and the $\mathrm{N}$ : $\mathrm{C}$ Redfield ratio $\left(\frac{16}{106}\right)$. For this relation, the $\lambda_{B A}$ parameter can be 0 (not included, original SCP-M), or 1 (included).

Finally, we have also included a feedback for the rain ratio, which is the fraction of calcifiers in the total biological production. In the original SCP-M this is a constant value for all boxes. Calcifiers can be limited in growth when $\mathrm{CO}_{3}^{2-}$ concentrations are too low. Ridgwell et al. (2007) model this limitation via the saturation state of $\mathrm{CaCO}_{3}$ as

$F_{C a, i}=\left(1-\lambda_{F}\right) \times F_{C a, b a s e}+\lambda_{F} \times 0.022\left(\frac{[C a]_{i}\left[C O_{3}^{2-}\right]_{i}}{K_{s p_{i}}}-1\right)^{0.81}, \quad i=1,2,5,7$

Here, $F_{C a}$ is the used rain ratio, and $F_{C a}$,base is the value used in the original SCP-M (0.07). The saturation state is determined via the concentrations of calcium ([Ca]), the carbonate ion concentration $\left[\mathrm{CO}_{3}^{2-}\right]$, and an equilibrium constant $K_{s p}$. In this 
feedback, $\lambda_{F}$ is either 0 (SCP-M) or 1 . The rain ratio feedback is a negative feedback. When carbonate concentrations increase in the surface layer, the rain ratio increases and therefore more calcium carbonate is removed from the surface layer effectively lowering the carbonate concentration.

\subsection{Parameter continuation methodology}

The SCP-M, including our representations of the additional feedbacks, leads to a system of ordinary differential equations of the form

$\frac{d \mathbf{u}}{d t}=\mathbf{f}(\mathbf{u}(t), \mathbf{p})$,

where $\mathbf{u}$ is the state vector (containing all the dependent quantities in all boxes), $\mathbf{f}$ contains the right-hand-side of the equations and $\mathbf{p}$ is the parameter vector. Usually, such models are integrated in time from a certain initial condition and the equilibrium behavior is determined for different values of the parameters. However, this is not very efficient to scan the parameter space and, moreover, it is difficult to detect tipping behavior. A much more efficient approach is to determine the equilibrium solutions directly versus parameters, avoiding time-integration, using continuation methods.

Here, we use the continuation and bifurcation software program AUTO to scan the parameter space and detect bifurcations efficiently (Doedel et al., 2007). The SCP-M is very suitable to be implemented into AUTO and to easily compute branches of equilibrium solutions, such as steady states of (10), versus parameters. The equations of the SCP-M turn out to have a singular Jacobian matrix (because both carbon, alkalinity and phosphate quantities are determined up to an additive constant), which requires to add integral conservation equations. We have added such integral conservation equations for carbon (DIC and atmospheric $\mathrm{pCO}_{2}$ ), Alk and $\mathrm{PO}_{4}^{3-}$ to the model equations to replace the equations for Box 4 . The conservation law for $\mathrm{PO}_{4}^{3-}$ is straightforward and already present in the model equations. The constant influx of $\mathrm{PO}_{4}^{3-}$ via the rivers is equal to the constant outflux via the sediments.

In the original SCP-M model, carbon and Alk are conserved in the ocean, atmosphere, continents, and sediments. However, the continental and sediment stocks are not explicitly represented in the version of the SCP-M we use. However, we can describe the change of total carbon and total Alk in the combined atmosphere and ocean stocks over time as

$$
\begin{aligned}
\frac{d T C}{d t} & =C_{\text {river }} \times V_{1}+\sum_{n=1}^{7}\left(C_{\text {carb }, n} \times V_{n}\right)+\sum_{n=1}^{7}\left(C_{\text {bio }, n} \times V_{n}\right) \\
\frac{d T A l k}{d t} & =A_{\text {river }} \times V_{1}+\sum_{n=1}^{7}\left(A_{\text {carb }, n} \times V_{n}\right)
\end{aligned}
$$

In these equations $T C$ and $T A l k$ are the total carbon and alkalinity in the system. As with $\mathrm{PO}_{4}^{3-}$, total carbon and Alk change due

to influx via the rivers $\left(C_{\text {river }}\right.$ and $\left.A_{\text {river }}\right)$ and outflux via the sediments. The carbon outflux via the sediments is determined by the sum of carbonate $\left(C_{c a r b}\right)$ and biological $\left(C_{b i o}\right)$ fluxes in the system. For Alk, the biological influence is absent. Model simulations with the original SCP-M have shown that the influence of the biological fluxes is negligible, i.e. all biologically produced organic matter is respired in the ocean itself. Therefore, this term can be set to zero in Equation (11a). This makes (11b) proportional to (11a) and hence we include only the latter and use it to determine the change in total Alk in the model. 
Table 2. Overview of the cases considered and their notation. The left column displays the used feedback. The other columns show the notation and what feedback are included in the case. The ' $\mathrm{x}$ ' in the notation is replaced with either P for the PI configuration, or L for the LGM configuration. Shaded columns indicate that this combination of feedbacks is also used for cases with a coupling between the AMOC and atmospheric $\mathrm{pCO}_{2}$ (Section 3.2). For these cases, ' $\mathrm{C}$ ' is added to either ' $\mathrm{P}$ ' or ' $\mathrm{L}$ ' to denote the coupling. The last column represents the feedback combinations used in Section 3.3. Case $\mathrm{x}-0$ is the original SCP-M.

\begin{tabular}{|c|ccccccccccccc|}
\hline Notation & $\mathrm{x}-0$ & $\mathrm{x}-1$ & $\mathrm{x}-2$ & $\mathrm{x}-3$ & $\mathrm{x}-4$ & $\mathrm{x}-5$ & $\mathrm{x}-6$ & $\mathrm{x}-7$ & $\mathrm{x}-8$ & $\mathrm{x}-9$ & $\mathrm{x}-10$ & $\mathrm{x}-11$ & $\mathrm{~L}-\mathrm{HB}$ \\
\hline$\lambda_{B I}$ & 0 & 1 & 0 & 0 & 0 & 0 & 1 & 1 & 1 & 1 & 1 & 1 & 1 \\
$\lambda_{T}$ & 0 & 0 & 1 & 0 & 0 & 0 & 1 & 0 & 0 & 0 & 1 & 1 & 2.085 \\
$\lambda_{P}$ & 0 & 0 & 0 & 1 & 0 & 0 & 0 & 1 & 0 & 0 & 1 & 0 & 1 \\
$\lambda_{B A}$ & 0 & 0 & 0 & 0 & 1 & 0 & 0 & 0 & 1 & 0 & 0 & 0 & 0 \\
$\lambda_{F}$ & 0 & 0 & 0 & 0 & 0 & 1 & 0 & 0 & 0 & 1 & 0 & 0 & 0 \\
$\lambda_{\epsilon}$ & 0 & 0 & 0 & 0 & 0 & 0 & 0 & 0 & 0 & 0 & 0 & 1 & 1.5 \\
$\lambda_{T 5}$ & 0 & 0 & 0 & 0 & 0 & 0 & 0 & 0 & 0 & 0 & 0 & 1 & 1 \\
\hline
\end{tabular}

We also changed the carbonate chemistry in the model. The original SCP-M uses the algorithm of Follows et al. (2006), which solves the carbonate chemistry by using hydrogen ion concentrations from a previous time step. Therefore, the algorithm is inherently transient and, since we directly solve for steady-state solutions, not suitable. We therefore adopted a simple 'textbook' carbonate chemistry based on carbonate alkalinity (Williams and Follows, 2011; Munhoven, 2013). This method approximates oceanic $\mathrm{pCO}_{2}$ by assuming that Alk is equal to carbonate alkalinity $\left(\mathrm{A}_{C}=\left[\mathrm{HCO}_{3}^{-}\right]+2\left[\mathrm{CO}_{3}^{2-}\right]\right)$. A disadvantage of this method is that $\mathrm{pH}$ values are generally a bit higher (0.15-0.2) than using more complicated algorithms (Munhoven, 2013). These higher $\mathrm{pH}$ values are one of the reasons our atmospheric $\mathrm{pCO}_{2}$ values are lower than in the original SCP-M (approximately $60 \mathrm{ppm}$ for case P-0 described in Section 3).

Eventually, by including (11a) and the overall conservation equations, the version of SCP-M used is a dynamical system with a state vector of dimension $d=20$. There is one equation for atmospheric $\mathrm{pCO}_{2}$, six for DIC, Alk and $\mathrm{PO}_{4}^{3-}$ in the ocean, and one equation for the total carbon content. Except for the new carbonate chemistry, the necessary changes made to the SCP-M do not change the outcome of the model compared to the original model. When the original model is fitted with the same carbonate chemistry based on carbonate alkalinity, the AUTO implementation and the original code produce the same results.

\section{Results}

In Section 3.1 we present the general sensitivity of atmospheric $\mathrm{pCO}_{2}$ to variations in the $\mathrm{AMOC}$ strength. We extend these results in Section 3.2 by adding a coupling between the AMOC strength and atmospheric $\mathrm{pCO}_{2}$. Internal variability found in the model will be presented in Section 3.3. An overview of all cases considered is given in Table 2. 


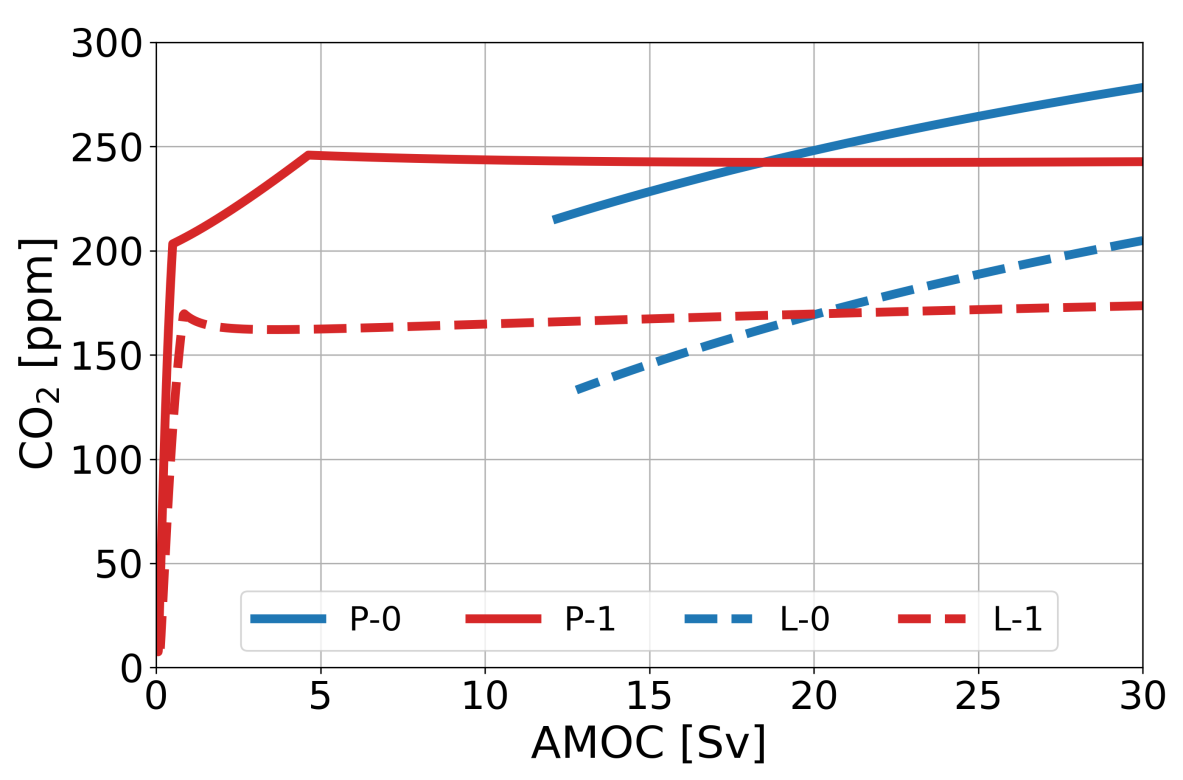

Figure 2. Atmospheric $\mathrm{pCO}_{2}$ in ppm under varying $\mathrm{AMOC}$ strength in $\mathrm{Sv}$ for two reference cases (blue: no feedback, red: with biological feedback) in two configurations (solid: PI, dashed: LGM).

\subsection{Sensitivity of atmospheric $\mathrm{pCO}_{2}$ to the $\mathrm{AMOC}$}

In this section the AMOC strength is used as a control parameter and steady states are calculated versus this parameter. For each configuration (PI and LGM) we use two reference cases ( $\mathrm{x}-0$, the original SCP-M configuration, and $\mathrm{x}-1$, with a different parameterization for biological production, in Table 2, where $\mathrm{x}$ is either $\mathrm{P}$ for the PI or L for the LGM configuration). The steady-state value of atmospheric $\mathrm{pCO}_{2}$ versus $\mathrm{AMOC}$ is shown for the reference cases in Fig. 2. For the cases where the biological feedback is not included, the solutions for smaller values of $\mathrm{AMOC}(<\sim 12 \mathrm{~Sv})$ display negative $\mathrm{PO}_{4}^{3-}$ concentrations in Box 2 and hence are not allowed. Such boundaries can be automatically monitored in AUTO and the continuation is stopped once a boundary is exceeded.

For the PI-configuration, Fig. 2 shows that, whereas $\mathrm{pCO}_{2}$ increases for larger AMOC strengths in case P-0, it remains fairly constant in P-1. Atmospheric $\mathrm{pCO}_{2}$ in case P-1 peaks around $5 \mathrm{~Sv}$, then decreases until approximately $20 \mathrm{~Sv}$ after which it increases slightly again. This different behavior occurs because, in case P-1, the AMOC has competing influences on DIC concentrations of the surface ocean. A first effect of an increasing AMOC is to increase the ventilation of the deep ocean, which also increases DIC concentrations in the surface layer. This promotes outgassing to the atmosphere. However, by increasing the AMOC strength, biological production in Boxes 2 and 7 is also increased. As a result, DIC and $\mathrm{PO}_{4}^{3-}$ are transported from the surface layer to the deep ocean. The first effect is dominant after $20 \mathrm{~Sv}$, and the second effect in the range of 5 to $20 \mathrm{~Sv}$. The absence of the second effect in P-0, explains the difference in sensitivity between P-0 and P-1. When we look at the other cases (Fig. 3a), we see that they either behave qualitatively like P-0 (cases P-2 to P-5), or P-1 (cases P-6 to P-11). Looking in 
(a)

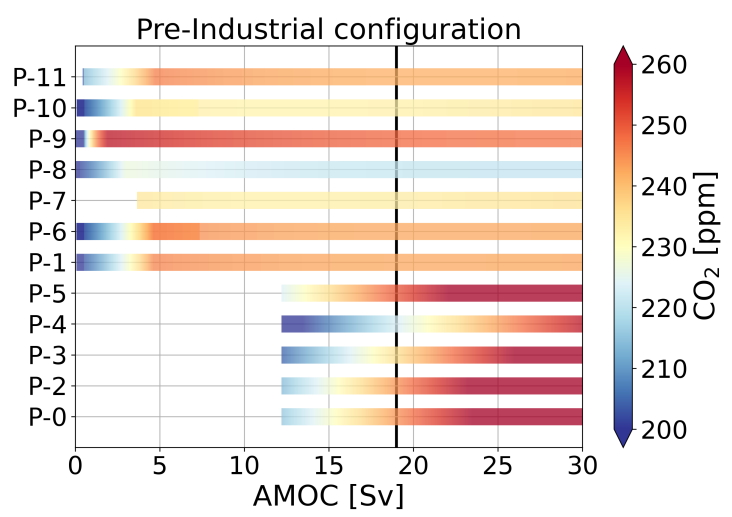

(b)

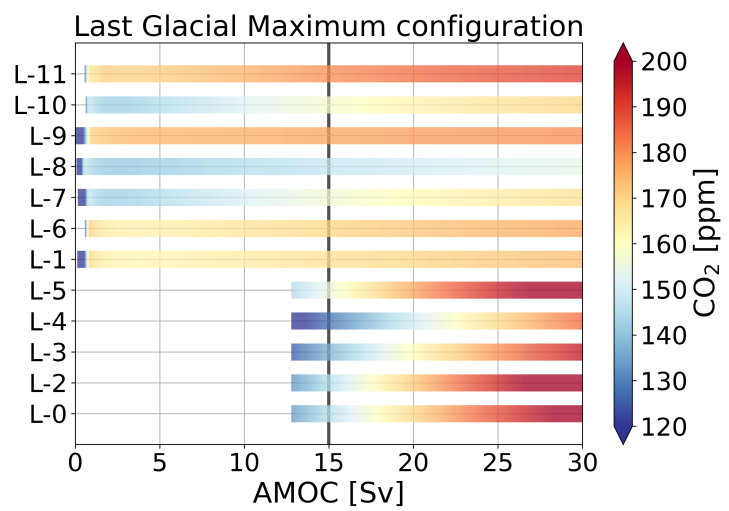

Figure 3. Atmospheric $\mathrm{pCO}_{2}$ in ppm (color shading) under varying AMOC strength in Sv for the cases considered in Table 2. (a) Preindustrial configuration. (b) Last Glacial Maximum configuration. Note that the range of the color shading differs between the two configurations and that some $\mathrm{CO}_{2}$ concentrations fall outside the displayed range. The AMOC range of the bars differ, because for some cases the steady solution becomes nonphysical (e.g. negative concentrations or large subzero temperature). The vertical black lines represent the AMOC strength in the original SPC-M.

more detail, we can see that when we include the rain ratio feedback (cases P-5, P-9) atmospheric $\mathrm{pCO}_{2}$ is higher, and when we include the biological influence on alkalinity, atmospheric $\mathrm{pCO}_{2}$ is lower (cases P-4, P-8). The results in Fig. 3a show that the biological feedback $\left(\lambda_{B I}=1\right)$ is the most dominant feedback in the PI configuration, i.e., including this feedback leads to a completely different sensitivity of the carbon cycle to changes in the AMOC strength.

For the LGM configuration (Fig. 2), two important differences with respect to the PI-configuration appear: (1) atmospheric $\mathrm{pCO}_{2}$ is approximately $80 \mathrm{ppm}$ lower, and (2) case L-1 has a different sensitivity than case P-1 for lower AMOC values. Where in P-1 atmospheric $\mathrm{pCO}_{2}$ decreases for an increasing AMOC between 5 and $20 \mathrm{~Sv}, \mathrm{~L}-1$ shows a monotonous increase of atmospheric $\mathrm{pCO}_{2}$ from $3 \mathrm{~Sv}$ onward. We see this different relation, because in the LGM-configuration, deep-ocean ventilation is lower due to a weaker GOC. Consequently, deep-ocean ventilation is more sensitive to changes in the AMOC. This eventually causes the different response of case L-1 with respect to case P-1. Cases L-2 to L-11 (Fig. 3b) relate to the L-0 and L-1 as in the PI-configuration. Fig. 3b shows that in the LGM configuration, as is the case in the PI configuration, the biological feedback is most dominant. The other feedbacks only influence the offset of $\mathrm{CO}_{2}$ concentrations, but do not result in large changes to the relation between the $\mathrm{AMOC}$ and atmospheric $\mathrm{pCO}_{2}$.

\subsection{Coupling AMOC - carbon cycle}

The AMOC strength depends also on atmospheric $\mathrm{pCO}_{2}$ and below we will discuss the steady state model solutions when a coupling between the AMOC and atmospheric $\mathrm{pCO}_{2}$ is applied. This coupling is based on how the AMOC responds to 
increasing atmospheric $\mathrm{pCO}_{2}$ in CMIP6 models (e.g. Bakker et al., 2016) and given by

$\psi_{2}=\psi_{2, \text { base }} \times\left(1-\lambda_{A} \times 0.1 \times 0.54 \times 5.35 \times \ln \frac{C O_{2}}{C_{2} O_{\text {base }}}\right)$

In this equation $\psi_{2, \text { base }}$ is a base value of the AMOC taken from the uncoupled case (where the AMOC is prescribed), $\psi_{2}$ is the actual AMOC strength in $\mathrm{m}^{3} / \mathrm{s}$ in the coupled case and $\lambda_{A}$ determines the strength of the coupling. We use three different values of $\lambda_{A}$ in this section: (1) 0 (no coupling), 1 (20\% decrease for a $\mathrm{CO}_{2}$ doubling), and $4\left(80 \%\right.$ decrease for a $\mathrm{CO}_{2}$ doubling). As the AMOC strength $\psi_{2}$ is now part of the state vector, we need other quantities as control parameters. We will use three different parameters here: (1) the rain ratio $\left(F_{C a}\right),(2)$ the biological production $(Z)$, and (3) the piston velocity $\left(k_{w}\right)$. We follow the steady-state solution in these parameters, where possible, between 0.1 to 10 times the reference value (indicated by the multiplier in Fig. 4). When we look at the effect of increasing $\lambda_{A}$, i.e. the coupling, we see that the general sensitivity of the solution to changes in model parameters decreases. This effect is best seen in case LC- 0 , but also present in the other cases, though less pronounced.

In Fig. $4 \mathrm{a}$ and $\mathrm{b}$ we plot the results when we continue the solutions in the rain ratio. There are no large differences between the different cases and configurations. Generally, we see two regimes. For low rain ratios, the solution is quite sensitive to changes in the rain ratio. Where the coloring in Fig. $4 \mathrm{a}$ and b is yellow (around $230 \mathrm{ppm}$ for the PI and around $140 \mathrm{ppm}$ for the LGM configuration), we see a shift: the solution becomes less sensitive to changes in the rain ratio. To explain the regimes of sensitivity, we note that the $\mathrm{CaCO}_{3}$ production is linearly related to the rain ratio. The production minus the dissolution of $\mathrm{CaCO}_{3}$ in the water column determines the outflux of Alk and DIC via the sediments. The different regimes can be explained by the amount of $\mathrm{CaCO}_{3}$ dissolution in the deep and abyssal ocean. For low rain ratios, we only have a constant dissolution. This makes the outflux of Alk and DIC linearly proportional to the production: if the rain ratio is low, the outflux is also low. This decrease in burial has to be compensated for by a weaker influx, i.e. a lower river influx. This is only possible when atmospheric $\mathrm{pCO}_{2}$ is lower. For larger rain ratios, we have both saturation dependent and constant dissolution in the subsurface boxes, i.e. more dissolution in the water column. Due to the variable dissolution, the outflux of Alk and DIC is no longer fully determined by $\mathrm{CaCO}_{3}$ production. This results in a lower sensitivity of the outflux to changes in the rain ratio. Therefore, atmospheric $\mathrm{pCO}_{2}$ is also less sensitive to the rain ratio.

For biological production as a control parameter (Fig. 4c and d) again all cases show comparable behavior. We can see that the parameter range for higher biological production is short. This is because $\mathrm{PO}_{4}^{3-}$ concentrations become negative at this point, even when we include the biological feedback. All cases have a maximum in atmospheric $\mathrm{pCO}_{2}$ around 0.7-0.8 times the original value. When the multiplier is lower than this value, we see a positive relation (higher biological production, higher atmospheric $\mathrm{pCO}_{2}$ ). For values larger than the maximum, we see an opposite relation, i.e. lower atmospheric $\mathrm{pCO}_{2}$ for higher biological production. We can explain the two sensitivity regimes via the same mechanism as in the previous paragraph. Biological production also influences $\mathrm{CaCO}_{3}$ production. The two regimes are different than for the rain ratio, since the effect of biological production on $\mathrm{CaCO}_{3}$ burial is two orders larger than the effect of the rain ratio on this burial. This means that changing the strength of biological production has a much larger effect on the process described above (in the previous paragraph) than changing the rain ratio. Again, increasing the AMOC coupling only reduces the sensitivity of the solutions. 
(a)

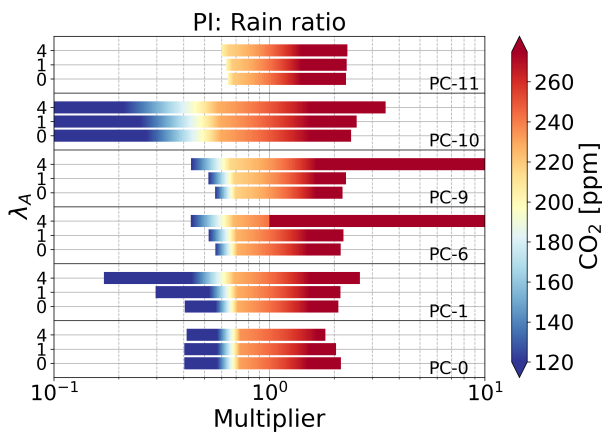

(c)

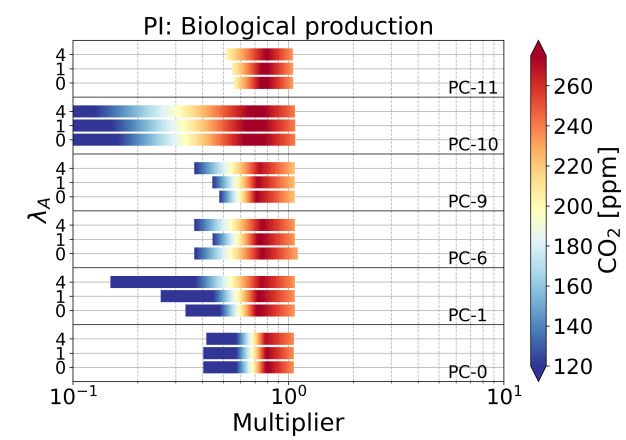

(e)

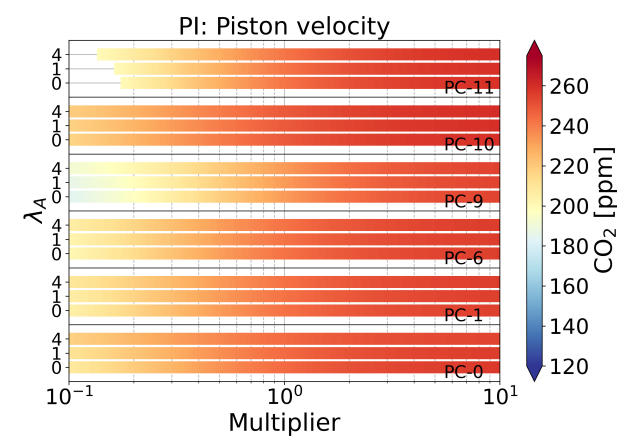

(b)

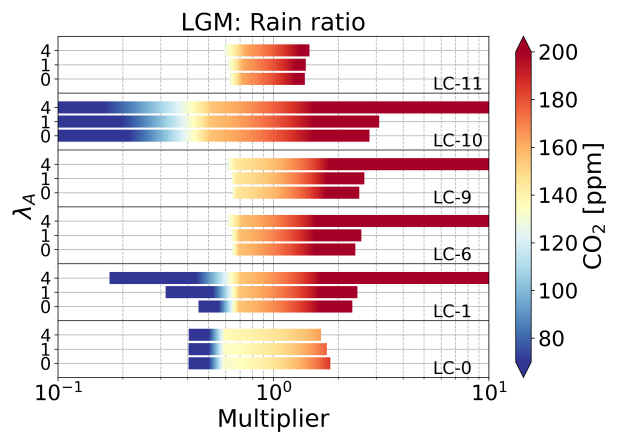

(d)

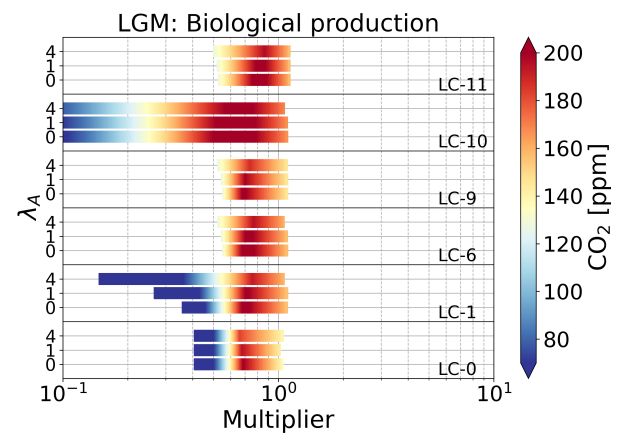

(f)

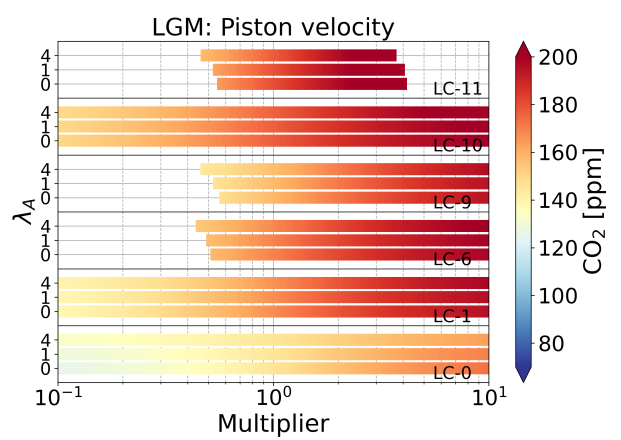

Figure 4. Atmospheric $\mathrm{pCO}_{2}$ in ppm (color shading) under varying parameter values. The left column represents cases of the PI configuration, and the right column of the LGM configuration. The top row shows cases where the strength of the rain ratio is varied between 0.1 and 10 times the original value. The other rows show the same but for cases where biological production (middle row) and the piston velocity (bottom row) are varied. In total 6 feedback combinations are used, denoted by the text within the graph. For each case, three different coupling strengths have been used: (1) $\lambda_{A}=0$, (2) $\lambda_{A}=1$, and (3) $\lambda_{A}=4$. 

logarithmic relation with higher sensitivities for lower piston velocities. The different feedback, configurations, and coupling strengths have the same effect as for the other two control parameters discussed above.

\subsection{Internal oscillation}

The feedback strengths we have used so far have been quite modest. The continuation methodology enables us to efficiently look at cases with different feedback strengths and to see whether different combinations can induce bifurcations in the carbon cycle. Especially in the LGM-configuration, when climate sensitivity $\left(\lambda_{T}\right)$ and the biological efficiency feedback $\left(\lambda_{\epsilon}\right)$ are increased, bifurcations arise on the branches of steady solutions. With case L-HB (for parameter values, see Table 2), we present an example where we find a supercritical Hopf Bifurcation (HB) around $13 \mathrm{~Sv}$ (Fig. 5a) in the uncoupled case $\left(\lambda_{A}=0\right.$, so the AMOC strength is a control parameter again). The HB produces a stable limit cycle extending to larger AMOC strengths with a period between 5,000 and 6,000 years where all state variables oscillate. In this section we look at the internal oscillation at $15 \mathrm{~Sv}$ (Fig. 5b). The oscillation has a period of 5,814 years, and atmospheric $\mathrm{pCO}_{2}$ has a range of $72 \mathrm{ppm}$.

The HB described in this section exists for a large range of parameter values and is thus robust. One important constraint on the existence of the bifurcation is the coupling strength between atmospheric $\mathrm{pCO}_{2}$ and biological production. This coupling comes down to the effect of atmospheric $\mathrm{pCO}_{2}$ on the biological efficiency $(\epsilon)$, which can be increased by increasing the temperature feedback $\left(\lambda_{T}\right)$ and/or the efficiency feedback $\left(\lambda_{\epsilon}\right)$. We do not find this bifurcation in the PI-configuration, because when the biology feedback $\left(\lambda_{B I}=1\right)$ is included, atmospheric $\mathrm{pCO}_{2}$ is insensitive to changes in the AMOC strength (case P-1, Fig. 2). Because of this low sensitivity, surface ocean temperature and biological efficiency are also insensitive to changes in the AMOC strength in the PI-configuration. Therefore, the coupling between the two is less effective in this configuration and we do not find a HB.

To explain the mechanism behind the oscillation, we have to look at the time-dependent solution of the model. What is important for this oscillation is the coupling between atmospheric $\mathrm{pCO}_{2}$ and the alkalinity cycle. Alkalinity influences the gas exchange between the ocean and the atmosphere via the carbonate chemistry and is, in turn, influenced by atmospheric $\mathrm{pCO}_{2}$ because the source and sink of alkalinity are coupled to $\mathrm{pCO}_{2}$. The source, the river influx, is directly proportional to atmospheric $\mathrm{pCO}_{2}$. The sink, i.e. outfluxing via the sediments, is related to $\mathrm{CaCO}_{3}$ burial, which is dependent on $\mathrm{CaCO}_{3}$ production in the surface ocean. Because this production is dependent on the biological efficiency, which is directly proportionate to atmospheric $\mathrm{pCO}_{2}$, the sink is also influenced by atmospheric $\mathrm{pCO}_{2}$. However, the effect of atmospheric $\mathrm{pCO}_{2}$ on the source and sink is opposite. When atmospheric $\mathrm{pCO}_{2}$ is high, the river influx is high, while the sediment outflux is low. This is key to the general mechanism sketched in Fig. 6 .

The results show that atmospheric $\mathrm{pCO}_{2}$ is affected by the amount of ingassing into Box 1 . Therefore, we start the explanation of the oscillation in Fig. 6 at this point. At the beginning of the oscillation (time $t=0$ in Fig. 6), ingassing in Box 1 starts to decrease. As a result, atmospheric $\mathrm{pCO}_{2}$ starts to increase approximately 200 years later. There is a delay, since atmospheric $\mathrm{pCO}_{2}$ is not solely determined by the gas exchange with Box 1 . The increase in atmospheric $\mathrm{pCO}_{2}$ has multiple effects. First of all, temperatures start to increase, which lower biological efficiency. This in turn reduces $\mathrm{CaCO}_{3}$ production, and thus the 
(a)

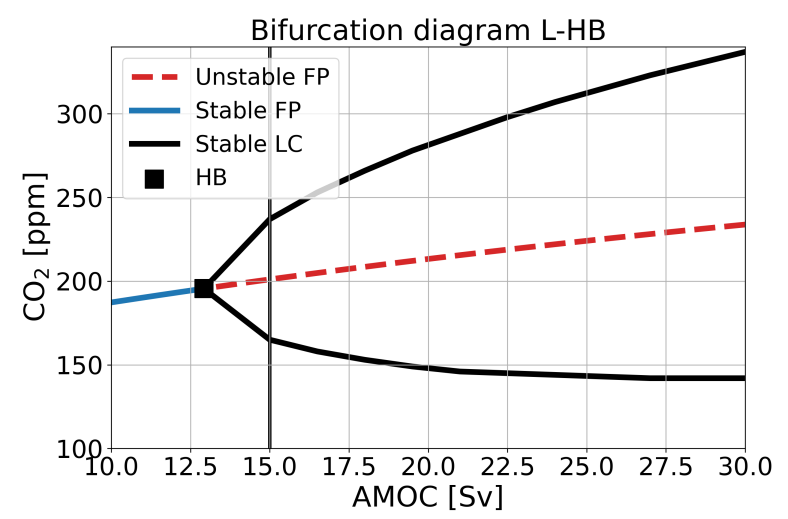

(b)

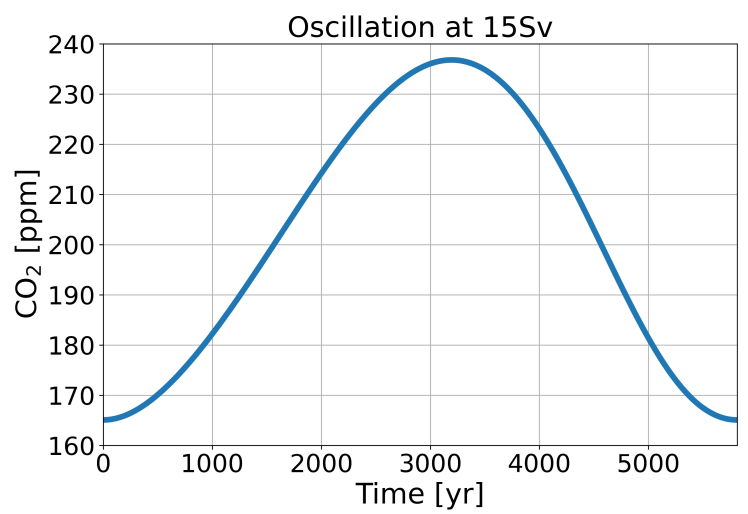

Figure 5. (a) Bifurcation diagram for case L-HB in atmospheric $\mathrm{pCO}_{2}$ - AMOC space. Blue, solid lines denote stable steady states (or fixed points, FPs); red, dashed lines indicate unstable steady states; black, solid lines indicate a stable limit cycle (LC), and the black square denotes the location of a (supercritical) Hopf Bifurcation (HB). (b) The oscillation of atmospheric $\mathrm{pCO}_{2}$ in ppm versus time in years for the limit cycle at $15 \mathrm{~Sv}$. The period is $5,814 \mathrm{yr}$.

sink of alkalinity is also reduced. Another effect of increasing atmospheric $\mathrm{pCO}_{2}$, is an increasing river flux, i.e. an increasing source of alkalinity into the ocean. After a quarter period (time $\mathrm{t}=\mathrm{T} / 4$ in Fig. 6), the source becomes larger than the sink, and total alkalinity in the ocean starts to increase. Meanwhile, atmospheric $\mathrm{pCO}_{2}$ is still increasing. As a result, the river influx also keeps increasing, while the sediment outflux keeps decreasing. After half a period (time $\mathrm{t}=\mathrm{T} / 2 \mathrm{in} \mathrm{Fig.} \mathrm{6),} \mathrm{oceanic} \mathrm{pCO} \mathrm{C}_{2}$ in Box 1 starts to decrease because alkalinity concentrations in Box 1 have increased. The lower oceanic $\mathrm{pCO}_{2}$ causes ingassing into Box 1 to increase, which in turn decreases atmospheric $\mathrm{pCO}_{2}$. The other half of the period is as explained above, but then the opposite.

In Fig. 7a, we can see that total alkalinity in the ocean lags atmospheric $\mathrm{pCO}_{2}$ by approximately a quarter period. In Fig. $7 \mathrm{~b}$ we can also see the anti-correlation between the source and sink of alkalinity to the ocean. Comparing the sink and source, we can clearly see a strong (anti-) correlation between atmospheric $\mathrm{pCO}_{2}$ and the (sink) source of alkalinity. The anti-correlation between the source and sink is the driving mechanism behind the oscillatory behavior. The time scale of the oscillation $(\sim$ 6,000 years) is related to the adjustment time of $\mathrm{CO}_{3}^{2-}$ to an imbalance between the influx and outflux of alkalinity and DIC in the ocean. This process, termed the calcium carbonate homeostat (Sarmiento and Gruber, 2006), has a timescale between 5 and $10 \mathrm{kyr}$ (Archer et al., 1997). The period of the internal oscillation corresponds well to this range.

\section{Summary and discussion}

In this study we investigated steady states of an extended version of the simple carbon cycle box model (SCP-M), where additional feedbacks have been included. Focus was on the relation between the $\mathrm{AMOC}$ and atmospheric pCO $\mathrm{P}_{2}$ for these 


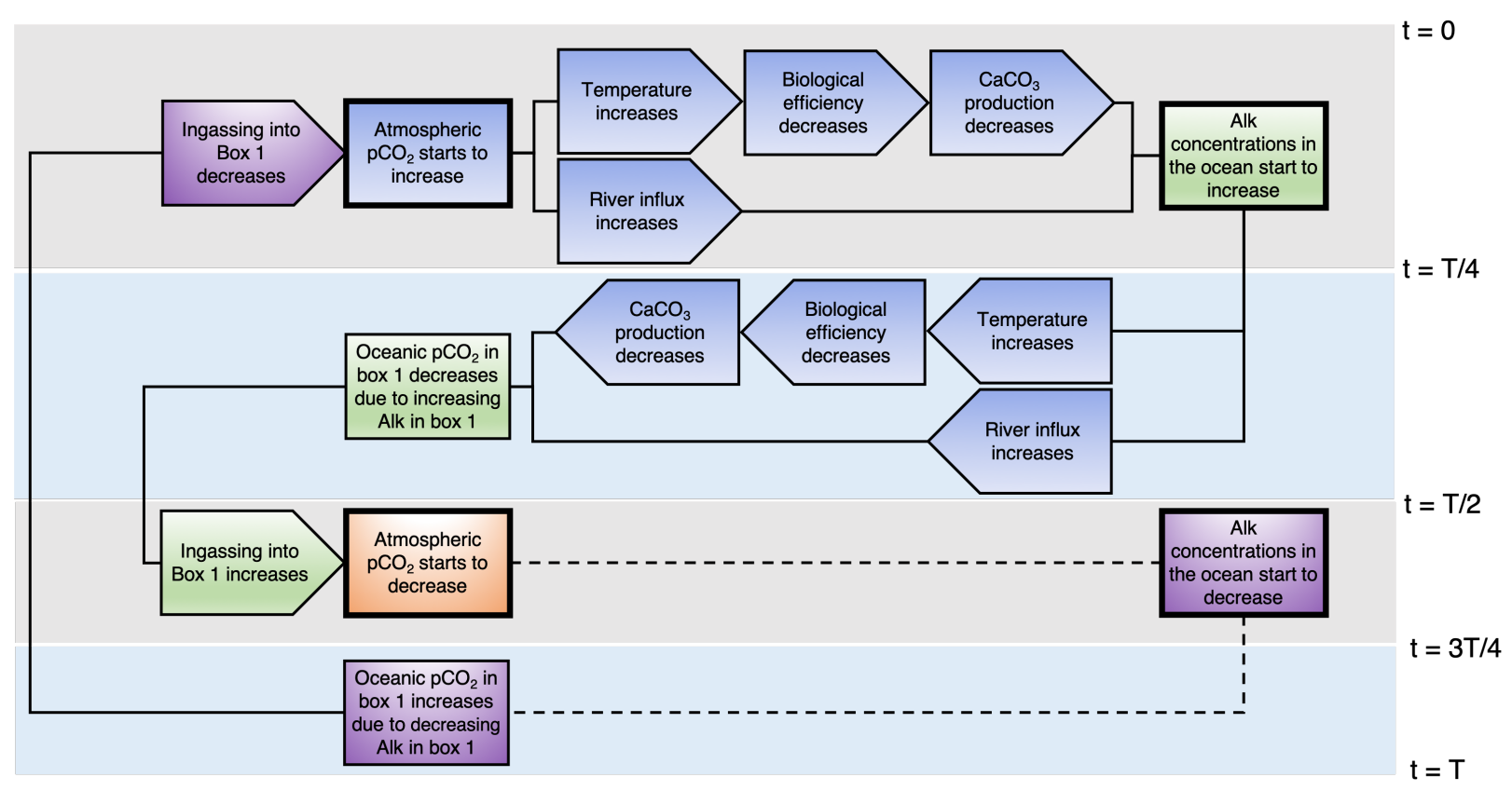

Figure 6. Schematic representation of the mechanism of the internal oscillation. The rectangles represent state variables, while the pointed blocks represent fluxes or model parameters. Some boxes have thicker outlining. These boxes cause a chain of events. The chain corresponding to the box, are the boxes with the same color shading. The gray and blue rectangles in the background represent a quarter period. In the second half of the period, processes are replaced with a dashed line. These processes are the opposite of what happens in the first half of the period.

steady states, with a special attention to the effect of feedbacks and climatic boundary conditions on this relation. Although the model we use is a simple box model, the original SCP-M was shown to be quite capable of simulating present-day observations and proxy data (LGM) (O’Neill et al., 2019).

With cases $\mathrm{x}-0$ to $\mathrm{x}-11$ (cf. Table 1 ) we looked into how the carbon cycle, and specifically atmospheric $\mathrm{pCO}_{2}$ responds to changes in the AMOC. These cases include different combinations of additional feedbacks. Our results (Section 3.1) suggest that the most important feedback, is the biological feedback, represented by equation (6). In both the PI and the LGM configurations, this feedback leads to a different sensitivity of atmospheric $\mathrm{pCO}_{2}$ to the AMOC (Fig. 2). Other feedbacks did not introduce large effects on the sensitivity (Fig. 3). This shows that biology can exert a large effect on atmospheric pCO . The results also show the importance of the climatic boundary conditions, as was already stated in Gottschalk et al. (2019). Generally, cases with the biological feedback (x-1, and x-6 to x-11) respond differently in the LGM configuration than in the PI configuration. This is related to the difference in deep ocean ventilation between the two configurations.

When a coupling between the AMOC and atmospheric $\mathrm{pCO}_{2}$ is included (Section 3.2), the pCO $\mathrm{CO}_{2}$ of the steady solutions becomes less sensitive to changes in model parameters $\left(k_{w}, Z, F_{C a}\right)$. This shows that the coupling works as a negative feedback in the carbon-cycle dynamics. What is interesting to see, is that the carbon cycle feedbacks do not have a large effect on 
(a)

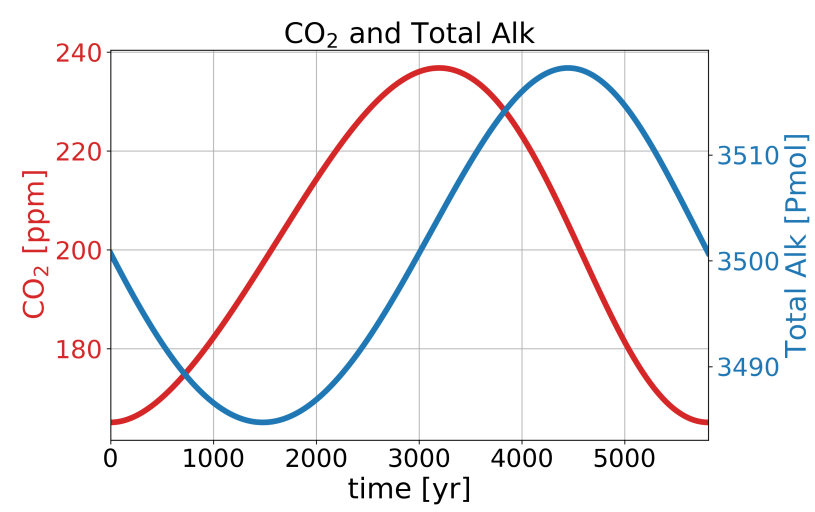

(b)

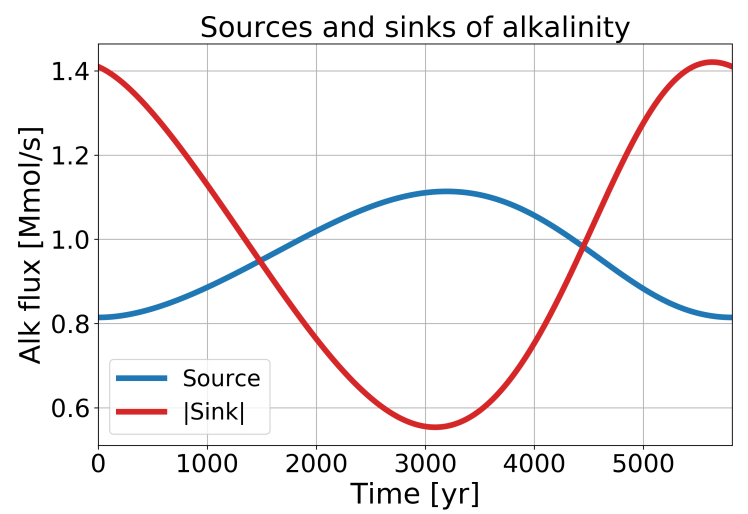

Figure 7. (a) Atmospheric $\mathrm{pCO}_{2}$ (red, left y-axis) in ppm, and total alkalinity (blue, right y-axis) in the ocean in Pmol for one oscillation. Total alkalinity lags $\mathrm{pCO}_{2}$ by approximately a quarter period. (b) The source (blue) and the absolute value of the sink (red) of alkalinity in the ocean. The source represents river influx, and the sink represents the sediment outflux. When the lines cross, i.e. around 1,500 yr and 4,400 years, total alkalinity in (a) has a minimum and a maximum respectively.

the AMOC- $\mathrm{pCO}_{2}$ relation. This implies that ocean circulation is very effective in damping changes in gas exchange $\left(k_{w}\right)$, biological $(Z)$ and $\mathrm{CaCO}_{3}\left(F_{C a}\right)$ production.

When considering bifurcations of the steady solutions, an important result is what we did not find: saddle-node bifurcations. Hence, although quite nonlinear carbon cycle processes have been captured in this model, no multiple equilibrium regimes and associated hysteresis occur. As a consequence, any sharp transition in carbon cycle quantities cannot be easily linked to a transition between different steady states. However, we did find internal oscillations in the model, in particular with a period of 5,000 to 6,000 years related to the $\mathrm{CaCO}_{3}$ homeostat (Fig. 6). Important for this oscillation is the process representation that $\mathrm{CaCO}_{3}$ production reduces for increasing temperatures, which is supported by studies that suggest a decreased production under high atmospheric $\mathrm{CO}_{2}$ concentrations (Barker and Elderfield, 2002). However, this assumption is under debate as there are studies that find an increased calcifier production for higher temperatures (Cole et al., 2018) in specific situations.

Linking this oscillation to proxy data is difficult, especially since the variation in atmospheric $\mathrm{pCO}_{2}$ is relatively high (72 ppm) for reasonable AMOC values. If we look for example at the record of the last glacial period, $\mathrm{pCO}_{2}$ variations are of the order of $20 \mathrm{ppm}$ (Bauska et al., 2021). The variation found in our model is closer to that during the Pleistocene glacial cycles, but on a much shorter time scale. The time scale is actually closer to that of the Heinrich events. It is therefore hard to find an oscillation like this in the past record, but this does not mean the mechanism is not relevant. If we look at more fundamental work, our mechanism shares similarities to the internal oscillation found in a conceptual model where only Alk and DIC are resolved (Rothman, 2019). The mechanism in Rothman (2019) is based on the imbalance between the influx and outflux of DIC in the surface ocean, and is thus comparable to our mechanism. The phase differences in our model between quantities in the carbonate system (i.e. DIC, $\mathrm{Alk}, \mathrm{pH}, \mathrm{CO}_{3}^{2-}, \mathrm{HCO}_{3}^{-}$, and $\mathrm{H}_{2} \mathrm{CO}_{3}$ ) in the top $250 \mathrm{~m}$ compare well to those in 
Rothman (2019) (not shown). However, the responsible processes are different. In Rothman (2019) there is an important role for respiration of organic matter. In our model, this flux is implicitly modeled and we can reconstruct a similar flux from the export production. This reconstructed flux has comparable phase differences with the carbonate content as in Rothman (2019), but the relative strength of the flux does not match the burial flux in our model. This means that the SCP-M captures a different internal oscillation. In Rothman (2019) there is an important role for the ballast feedback because it couples the sources and sinks of DIC using the carbonate-ion concentration. In our oscillation, it is not the ballast feedback that drives the oscillation, but the $\mathrm{CaCO}_{3}$ homeostat, coupling the sources and sinks of alkalinity through atmospheric $\mathrm{pCO}_{2}$.

In conclusion, we have found that the relation between atmospheric $\mathrm{pCO}_{2}$ and the $\mathrm{AMOC}$ strength relies mostly on biological processes and climatic boundary conditions. Therefore, we suggest that by comparing results of different models, special attention should be given to the way biological production is represented. Our most interesting result is the discovery of an internal oscillation in the carbon cycle and we hope that the mechanism behind this oscillation will stimulate further model work and be useful for explaining past atmospheric $\mathrm{pCO}_{2}$ variability.

Code and data availability. The original version of the SPC-M is available at https://doi.org/10.5281/zenodo.1310161, the AUTO implementation is available at https://github.com/dboot0016/SCPM-AUTO (Boot et al., 2021). AUTO can be downloaded from https://sourceforge. net/projects/auto-07p/.

\section{Appendix A: Model parameters}

In this appendix values and descriptions of the parameters in the extended SCP-M are given. In Tables A1 to A3 the parameter values used in our model are presented. The values presented here are for the pre-industrial configuration. The parameter values that are different in the Last Glacial Maximum configuration are presented in Table 1. All parameter values, except the biological efficiency $(\epsilon)$ parameters, are taken from the SCP-M. The biological efficiency parameters have been fitted such that $Z$ in equation 6 is equal to $Z_{b a s e}$ under the original parameter values in the SCP-M. When determining the value of $\epsilon_{2, b a s e}$, we also took the effect of the biological production in the North Pacific into account, which leads to a value of $\epsilon_{2, b a s e}>1$. In Table A4 we also present the literature where the expressions for the equilibrium constants were taken from. 
Table A1. Symbol (column 1), description (column 2), value (column 3), and units (column 4) of the general parameters used in our model.

\begin{tabular}{|c|c|c|c|}
\hline Symbol & Description & Value & Units \\
\hline$V_{a t}$ & Volume of the atmosphere & $1.76 \times 10^{20}$ & $\mathrm{~m}^{3}$ \\
\hline$\rho$ & Sea water density & 1029 & $\mathrm{~kg} \mathrm{~m}^{-3}$ \\
\hline$F_{C a, b a s e}$ & Base rain ratio & 0.07 & - \\
\hline$n$ & Order of $\mathrm{CaCO}_{3}$ dissolution kinetics & 1 & - \\
\hline$P_{C}$ & Mass percentage of $\mathrm{C}$ in $\mathrm{CaCO}_{3}$ & 0.12 & - \\
\hline$D_{C a}$ & Constant dissolution rate of $\mathrm{CaCO}_{3}$ & $2.75 \times 10^{-13}$ & $\mathrm{~mol} \mathrm{~m} \mathrm{~m}^{-3} \mathrm{~s}^{-1}$ \\
\hline$W_{S C}$ & Constant silicate weathering & $2.4 \times 10^{-12}$ & $\mathrm{~mol} \mathrm{~m}^{-3} \mathrm{~s}^{-1}$ \\
\hline$W_{S V}$ & Variable silicate weathering parameter & $1.6 \times 10^{-8}$ & $\mathrm{~mol} \mathrm{~m}^{-3} \mathrm{~atm}^{-1} \mathrm{~s}^{-1}$ \\
\hline$W_{C V}$ & Variable carbonate weathering parameter & $6.3 \times 10^{-8}$ & $\mathrm{~mol} \mathrm{~m}^{-3} \mathrm{~atm}^{-1} \mathrm{~s}^{-1}$ \\
\hline$k_{\mathrm{CaCO} 3}$ & Constant $\mathrm{CaCO}_{3}$ dissolution rate & $4.4 \times 10^{-6}$ & $\mathrm{~s}^{-1}$ \\
\hline$R_{P O 4}$ & River influx of $\mathrm{PO}_{4}^{3-}$ & $1.5 \times 10^{4}$ & \\
\hline$b$ & Exponent in Martin's law & 0.75 & - \\
\hline$d_{0}$ & Reference depth for biological productivity & 100 & $\mathrm{~m}$ \\
\hline$\alpha$ & Fraction of the GOC that flows through Box 7 & 0.5 & - \\
\hline$\gamma_{1}$ & Bidirectional mixing between Box 4 and 6 & 29 & Sv \\
\hline$\gamma_{2}$ & Bidirectional mixing between Box 1 and 3 & 40 & $\mathrm{~Sv}$ \\
\hline$\psi_{1}$ & General overturning circulation & 29 & Sv \\
\hline$\psi_{2, \text { base }}$ & Base value of the Atlantic Meridional Overturning Circulation & 19 & Sv \\
\hline$k_{w, \text { base }}$ & Base piston velocity & 3 & $\mathrm{~m} /$ day \\
\hline$R_{C: P}$ & Redfield C:P ratio & 130 & $\mathrm{~mol} \mathrm{C} / \mathrm{mol} \mathrm{P}$ \\
\hline$R_{P: C}$ & Redfield P:C ratio & $1 / 130$ & $\mathrm{~mol} \mathrm{P} / \mathrm{mol} \mathrm{C}$ \\
\hline
\end{tabular}


Table A2. Symbol (column 1), description (column 2), value (column 3), and units (column 4) of parameters concerning the dimensions of the boxes used in our model.

\begin{tabular}{|c|c|c|c|}
\hline Symbol & Description & Value & Units \\
\hline$V_{1}$ & Volume of Box 1 & $2.71425 \times 10^{16}$ & $\mathrm{~m}^{3}$ \\
\hline$V_{2}$ & Volume of Box 2 & $9.0475 \times 10^{15}$ & $\mathrm{~m}^{3}$ \\
\hline$V_{3}$ & Volume of Box 3 & $2.442825 \times 10^{17}$ & $\mathrm{~m}^{3}$ \\
\hline$V_{4}$ & Volume of Box 4 & $5.699925 \times 10^{17}$ & $\mathrm{~m}^{3}$ \\
\hline$V_{5}$ & Volume of Box 5 & $4.523750 \times 10^{16}$ & $\mathrm{~m}^{3}$ \\
\hline$V_{6}$ & Volume of Box 6 & $5.4285 \times 10^{17}$ & $\mathrm{~m}^{3}$ \\
\hline$V_{7}$ & Volume of Box 7 & $9.0475 \times 10^{15}$ & $\mathrm{~m}^{3}$ \\
\hline$A_{1}$ & Surface area Box 1 & $2.71425 \times 10^{14}$ & $\mathrm{~m}^{2}$ \\
\hline$A_{2}$ & Surface area Box 2 & $3.619 \times 10^{13}$ & $\mathrm{~m}^{2}$ \\
\hline$A_{3}$ & Surface area Box 3 & $2.71425 \times 10^{14}$ & $\mathrm{~m}^{2}$ \\
\hline$A_{4}$ & Surface area Box 4 & $3.43805 \times 10^{14}$ & $\mathrm{~m}^{2}$ \\
\hline$A_{5}$ & Surface area Box 5 & $1.8095 \times 10^{13}$ & $\mathrm{~m}^{2}$ \\
\hline$A_{6}$ & Surface area Box 6 & $3.619 \times 10^{14}$ & $\mathrm{~m}^{2}$ \\
\hline$A_{7}$ & Surface area Box 7 & $3.619 \times 10^{13}$ & $\mathrm{~m}^{2}$ \\
\hline$d_{f 1}$ & Floor depth Box 1 & 100 & $\mathrm{~m}$ \\
\hline$d_{f 2}$ & Floor depth Box 2 & 250 & $\mathrm{~m}$ \\
\hline$d_{f 3}$ & Floor depth Box 3 & 1000 & $\mathrm{~m}$ \\
\hline$d_{f 4}$ & Floor depth Box 4 & 2500 & $\mathrm{~m}$ \\
\hline$d_{f 5}$ & Floor depth Box 5 & 2500 & $\mathrm{~m}$ \\
\hline$d_{f 6}$ & Floor depth Box 6 & 4000 & $\mathrm{~m}$ \\
\hline$d_{f 7}$ & Floor depth Box 7 & 250 & $\mathrm{~m}$ \\
\hline$d_{c 3}$ & Ceiling depth Box 3 & 100 & $\mathrm{~m}$ \\
\hline$d_{c 4,1}$ & Ceiling depth Box 4 (below Boxes 2 and 7) & 250 & $\mathrm{~m}$ \\
\hline$d_{c 4,2}$ & Ceiling depth Box 4 (below Box 3) & 1000 & $\mathrm{~m}$ \\
\hline$d_{c 6}$ & Ceiling depth Box 6 & 2500 & $\mathrm{~m}$ \\
\hline
\end{tabular}


Table A3. Symbol (column 1), description (column 2), value (column 3), and units (column 4) of the other parameters used in our model.

\begin{tabular}{|llll|}
\hline Symbol & Description & Value & Units \\
\hline$Z_{1, \text { base }}$ & Base biological production Box 1 & 1.1 & $\mathrm{~mol} \mathrm{C} \mathrm{m}^{-2} \mathrm{yr}^{-1}$ \\
$Z_{2, \text { base }}$ & Base biological production Box 2 & 4.5 & $\mathrm{~mol} \mathrm{C} \mathrm{m}^{-2} \mathrm{yr}^{-1}$ \\
$Z_{5, \text { base }}$ & Base biological production Box 5 & 1.75 & $\mathrm{~mol} \mathrm{C} \mathrm{m}^{-2} \mathrm{yr}^{-1}$ \\
$Z_{7, \text { base }}$ & Base biological production Box 7 & 5.325 & $\mathrm{~mol} \mathrm{C} \mathrm{m}^{-2} \mathrm{yr}^{-1}$ \\
$\epsilon_{1, \text { base }}$ & Base biological efficiency Box 1 & 0.9 & - \\
$\epsilon_{2, \text { base }}$ & Base biological efficiency Box 2 & 1.25 & - \\
$\epsilon_{5, \text { base }}$ & Base biological efficiency Box 5 & 0.35 & - \\
$\epsilon_{7, \text { base }}$ & Base biological efficiency Box 7 & 0.62 & - \\
$T_{1, \text { base }}$ & Base temperature Box 1 & 23.34 & ${ }^{\circ} \mathrm{C}$ \\
$T_{2, b a s e}$ & Base temperature Box 2 & 9.1 & ${ }^{\circ} \mathrm{C}$ \\
$T_{3}$ & Temperature Box 3 & 11.28 & ${ }^{\circ} \mathrm{C}$ \\
$T_{4}$ & Temperature Box 4 & 3.24 & ${ }^{\circ} \mathrm{C}$ \\
$T_{5, \text { base }}$ & Base temperature Box 5 & 0.93 & ${ }^{\circ} \mathrm{C}$ \\
$T_{6}$ & Temperature Box 6 & 1.8 & ${ }^{\circ} \mathrm{C}$ \\
$T_{7, b a s e}$ & Base temperature Box 7 & 5.83 & ${ }^{\circ} \mathrm{C}$ \\
$S_{1}$ & Salinity Box 1 & 35.25 & $\mathrm{~g} \mathrm{~kg}^{-1}$ \\
$S_{2}$ & Salinity Box 2 & 34.27 & $\mathrm{~g} \mathrm{~kg}^{-1}$ \\
$S_{3}$ & Salinity Box 3 & 34.91 & $\mathrm{~g} \mathrm{~kg}^{-1}$ \\
$S_{4}$ & Salinity Box 4 & 34.76 & $\mathrm{~g} \mathrm{~kg}^{-1}$ \\
$S_{5}$ & Salinity Box 5 & 34.43 & $\mathrm{~g} \mathrm{~kg}^{-1}$ \\
$S_{6}$ & Salinity Box 6 & 34.77 & $\mathrm{~g} \mathrm{~kg}^{-1}$ \\
$S_{7}$ & Salinity Box 7 & 34.17 & $\mathrm{~g} \mathrm{~kg}^{-1}$ \\
{$[\mathrm{Ca}]_{1}$} & Calcium concentration Box 1 & 10.96 & $\mathrm{~mol} \mathrm{~m}^{-3}$ \\
{$[\mathrm{Ca}]_{2}$} & Calcium concentration Box 2 & 10.66 & $\mathrm{~mol} \mathrm{~m}^{-3}$ \\
{$[C a]_{3}$} & Calcium concentration Box 3 & 10.55 & $\mathrm{~mol} \mathrm{~m}^{-3}$ \\
{$[C a]_{4}$} & Calcium concentration Box 4 & 10.51 & $\mathrm{~mol} \mathrm{~m}^{-3}$ \\
{$[C a]_{5}$} & Calcium concentration Box 5 & 10.71 & $\mathrm{~mol} \mathrm{~m}^{-3}$ \\
{$[C a]_{6}$} & Calcium concentration Box 6 & 10.51 & $\mathrm{~mol} \mathrm{~m}^{-3}$ \\
{$[\text { Ca }]_{7}$} & Calcium concentration Box 7 & 10.63 & $\mathrm{~mol} \mathrm{~m}^{-3}$ \\
\hline & & & \\
\hline
\end{tabular}


https://doi.org/10.5194/esd-2021-42

Preprint. Discussion started: 8 July 2021

(c) Author(s) 2021. CC BY 4.0 License.

Table A4. The symbols and description of the equilibrium constants are presented in the first two columns. The third column presents the source of the used expression.

\begin{tabular}{|lll|}
\hline Symbol & Description & Expression \\
\hline$K_{0}$ & Solubility constant & Weiss (1974) \\
$K_{1}$ & First dissociation constant of carbonic acid & Lueker et al. (2000) \\
$K_{2}$ & Second dissociation constant of carbonic acid & Lueker et al. (2000) \\
$K_{s p, b a s e}$ & Equilibrium constant for $\mathrm{CaCO}_{3}$ dissolution & Mucci (1983) \\
$K_{\text {sp,press }}$ & Pressure correction for $K_{s p, b a s e}$ & Millero (1983) \\
\hline
\end{tabular}

Author contributions. DB and HD designed the study and constructed the AUTO version of the SPC-M. DB obtained and analysed all the results. DB and HD wrote the first version of the paper; all authors contributed to the writing of the final paper.

Competing interests. The authors declare that they have no conflict of interest. 


\section{References}

Archer, D., Kheshgi, H., and Maier-Reimer, E.: Multiple timescales for neutralization of fossil fuel CO2, Geophysical Research Letters, 24, 405-408, https://doi.org/https://doi.org/10.1029/97GL00168, https://doi.org/10.1029/97GL00168, 1997.

Bakker, P., Schmittner, A., Lenaerts, J. T. M., Abe-Ouchi, A., Bi, D., van den Broeke, M. R., Chan, W.-L., Hu, A., Beadling, R. L., Marsland, S. J., Mernild, S. H., Saenko, O. A., Swingedouw, D., Sullivan, A., and Yin, J.: Fate of the Atlantic Meridional Overturning Circulation: Strong decline under continued warming and Greenland melting, Geophysical Research Letters, 43, 12,212-252,260, https://doi.org/https://doi.org/10.1002/2016GL070457, https://doi.org/10.1002/2016GL070457, 2016.

Barker, S. and Elderfield, H.: Foraminiferal Calcification Response to Glacial-Interglacial Changes in Atmospheric CO2, Science, 297, 833 LP - 836, https://doi.org/10.1126/science.1072815, http://science.sciencemag.org/content/297/5582/833.abstract, 2002.

Bauska, T. K., Marcott, S. A., and Brook, E. J.: Abrupt changes in the global carbon cycle during the last glacial period, Nature Geoscience, 14, 91-96, https://doi.org/10.1038/s41561-020-00680-2, https://doi.org/10.1038/s41561-020-00680-2, 2021.

Boot, D., Von der Heydt, A. S., and Dijkstra, H. A.: SCPM-AUTO-ESD, https://doi.org/10.5281/zenodo.4972553, 2021.

Cael, B. B., Bisson, K., and Follows, M. J.: How have recent temperature changes affected the efficiency of ocean biological carbon export?, Limnology and Oceanography Letters, 2, 113-118, https://doi.org/https://doi.org/10.1002/lol2.10042, https://doi.org/10.1002/lol2.10042, 2017.

Cole, C., Finch, A. A., Hintz, C., Hintz, K., and Allison, N.: Effects of seawater pCO2 and temperature on calcification and productivity in the coral genus Porites spp.: an exploration of potential interaction mechanisms, Coral Reefs, 37, 471-481, https://doi.org/10.1007/s00338018-1672-3, https://doi.org/10.1007/s00338-018-1672-3, 2018.

Doedel, E. J., Paffenroth, R. C., Champneys, A. C., Fairgrieve, T. F., Kuznetsov, Y. A., Oldeman, B. E., Sandstede, B., and Wang, X. J.: AUTO-07p: Continuation and Bifurcation Software for Ordinary Differential Equations, 2007.

Duplessy, J. C., Shackleton, N. J., Fairbanks, R. G., Labeyrie, L., Oppo, D., and Kallel, N.: Deepwater source variations during the last climatic cycle and their impact on the global deepwater circulation, Paleoceanography, 3, 343-360, https://doi.org/https://doi.org/10.1029/PA003i003p00343, https://doi.org/10.1029/PA003i003p00343, 1988.

Follows, M. J., Ito, T., and Dutkiewicz, S.: On the solution of the carbonate chemistry system in ocean biogeochemistry models, Ocean Modelling, 12, 290-301, https://doi.org/https://doi.org/10.1016/j.ocemod.2005.05.004, http://www.sciencedirect.com/science/article/pii/ S1463500305000533, 2006.

Friedlingstein, P., O’Sullivan, M., Jones, M. W., Andrew, R. M., Hauck, J., Olsen, A., Peters, G. P., Peters, W., Pongratz, J., Sitch, S., Le Quéré, C., Canadell, J. G., Ciais, P., Jackson, R. B., Alin, S., Aragão, L. E. O. C., Arneth, A., Arora, V., Bates, N. R., Becker, M., Benoit-Cattin, A., Bittig, H. C., Bopp, L., Bultan, S., Chandra, N., Chevallier, F., Chini, L. P., Evans, W., Florentie, L., Forster, P. M., Gasser, T., Gehlen, M., Gilfillan, D., Gkritzalis, T., Gregor, L., Gruber, N., Harris, I., Hartung, K., Haverd, V., Houghton, R. A., Ilyina, T., Jain, A. K., Joetzjer, E., Kadono, K., Kato, E., Kitidis, V., Korsbakken, J. I., Landschützer, P., Lefèvre, N., Lenton, A., Lienert, S., Liu, Z., Lombardozzi, D., Marland, G., Metzl, N., Munro, D. R., Nabel, J. E. M. S., Nakaoka, S.-I., Niwa, Y., O’Brien, K., Ono, T., Palmer, P. I., Pierrot, D., Poulter, B., Resplandy, L., Robertson, E., Rödenbeck, C., Schwinger, J., Séférian, R., Skjelvan, I., Smith, A. J. P., Sutton, A. J., Tanhua, T., Tans, P. P., Tian, H., Tilbrook, B., van der Werf, G., Vuichard, N., Walker, A. P., Wanninkhof, R., Watson, A. J., https://doi.org/10.5194/essd-12-3269-2020, https://essd.copernicus.org/articles/12/3269/2020/, 2020. 
Ganachaud, A. and Wunsch, C.: Improved estimates of global ocean circulation, heat transport and mixing from hydrographic data, Nature, 408, 453-457, https://doi.org/10.1038/35044048, https://doi.org/10.1038/35044048, 2000.

Gottschalk, J., Battaglia, G., Fischer, H., Frölicher, T. L., Jaccard, S. L., Jeltsch-Thömmes, A., Joos, F., Köhler, P., Meissner, K. J., Menviel, L., Nehrbass-Ahles, C., Schmitt, J., Schmittner, A., Skinner, L. C., and Stocker, T. F.: Mechanisms of millennial-scale atmospheric CO2 change in numerical model simulations, Quaternary Science Reviews, 220, 30-74, https://doi.org/https://doi.org/10.1016/j.quascirev.2019.05.013, http://www.sciencedirect.com/science/article/pii/S0277379118310473, 2019.

Gregory, J. M., Dixon, K. W., Stouffer, R. J., Weaver, A. J., Driesschaert, E., Eby, M., Fichefet, T., Hasumi, H., Hu, A., Jungclaus, J. H., Kamenkovich, I. V., Levermann, A., Montoya, M., Murakami, S., Nawrath, S., Oka, A., Sokolov, A. P., and Thorpe, R. B.: A model intercomparison of changes in the Atlantic thermohaline circulation in response to increasing atmospheric CO2 concentration, Geophysical Research Letters, 32, https://doi.org/https://doi.org/10.1029/2005GL023209, https://doi.org/10.1029/2005GL023209, 2005.

Gruber, N., Landschützer, P., and Lovenduski, N. S.: The Variable Southern Ocean Carbon Sink, Annual Review of Marine Science, 11, 159-186, https://doi.org/10.1146/annurev-marine-121916-063407, https://doi.org/10.1146/annurev-marine-121916-063407, 2019.

Huiskamp, W. N. and Meissner, K. J.: Oceanic carbon and water masses during the Mystery Interval: A model-data comparison study, Paleoceanography, 27, https://doi.org/https://doi.org/10.1029/2012PA002368, https://doi.org/10.1029/2012PA002368, 2012.

Jiang, X. and Yung, Y. L.: Global Patterns of Carbon Dioxide Variability from Satellite Observations, Annual Review of Earth and Planetary Sciences, 47, 225-245, https://doi.org/10.1146/annurev-earth-053018-060447, https://doi.org/10.1146/annurev-earth-053018-060447, 2019.

Kwon, E. Y. and Primeau, F.: Optimization and sensitivity of a global biogeochemistry ocean model using combined in situ DIC, alkalinity, and phosphate data, Journal of Geophysical Research: Oceans, 113, https://doi.org/https://doi.org/10.1029/2007JC004520, https://doi.org/ 10.1029/2007JC004520, 2008.

Lueker, T. J., Dickson, A. G., and Keeling, C. D.: Ocean pCO2 calculated from dissolved inorganic carbon, alkalinity, and equations for $\mathrm{K} 1$ and K2: validation based on laboratory measurements of CO2 in gas and seawater at equilibrium, Marine Chemistry, 70, 105-119, https://doi.org/https://doi.org/10.1016/S0304-4203(00)00022-0, https://www.sciencedirect.com/science/article/pii/S0304420300000220, 2000.

Marchal, O., Stocker, T. F., and Joos, F.: Impact of oceanic reorganizations on the ocean carbon cycle and atmospheric carbon dioxide content, Paleoceanography, 13, 225-244, https://doi.org/https://doi.org/10.1029/98PA00726, https://doi.org/10.1029/98PA00726, 1998.

Mariotti, V., Bopp, L., Tagliabue, A., Kageyama, M., and Swingedouw, D.: Marine productivity response to Heinrich events: a model-data comparison, Climate of the Past, 8, 1581-1598, https://doi.org/10.5194/cp-8-1581-2012, https://cp.copernicus.org/articles/8/1581/2012/, 2012.

Martin, J. H., Knauer, G. A., Karl, D. M., and Broenkow, W. W.: VERTEX: carbon cycling in the northeast Pacific, Deep Sea Research Part A. Oceanographic Research Papers, 34, 267-285, https://doi.org/https://doi.org/10.1016/0198-0149(87)90086-0, http://www.sciencedirect. com/science/article/pii/0198014987900860, 1987.

Menviel, L., Timmermann, A., Mouchet, A., and Timm, O.: Meridional reorganizations of marine and terrestrial productivity during Heinrich events, Paleoceanography, 23, https://doi.org/https://doi.org/10.1029/2007PA001445, https://doi.org/10.1029/2007PA001445, 2008.

Menviel, L., England, M. H., Meissner, K. J., Mouchet, A., and Yu, J.: Atlantic-Pacific seesaw and its role in outgassing CO2 during Heinrich events, Paleoceanography, 29, 58-70, https://doi.org/https://doi.org/10.1002/2013PA002542, https://doi.org/10.1002/2013PA002542, 2014. 
Millero, F. J.: CHAPTER 43 - Influence of Pressure on Chemical Processes in the Sea, pp. 1-88, Academic Press, https://doi.org/https://doi.org/10.1016/B978-0-12-588608-6.50007-9, https://www.sciencedirect.com/science/article/pii/ B9780125886086500079, 1983.

Mucci, A.: The solubility of calcite and aragonite in seawater at various salinities, temperatures, and one atmosphere total pressure, American Journal of Science, 283, 780-799, https://doi.org/10.2475/ajs.283.7.780, https://ui.adsabs.harvard.edu/abs/1983AmJS..283..780M, 1983.

Muller, R. A. and MacDonald, G. J.: Ice Ages and Astronomical Causes, Springer-Verlag, 2000.

Munhoven, G.: Mathematics of the total alkalinity-pH equation - pathway to robust and universal solution algorithms: the SolveSAPHE package v1.0.1, Geoscientific Model Development, 6, 1367-1388, https://doi.org/10.5194/gmd-6-1367-2013, https://gmd.copernicus.org/ articles/6/1367/2013/, 2013.

Nielsen, S. B., Jochum, M., Pedro, J. B., Eden, C., and Nuterman, R.: Two-Timescale Carbon Cycle Response to an AMOC Collapse, Paleoceanography and Paleoclimatology, 34, 511-523, https://doi.org/https://doi.org/10.1029/2018PA003481, https://doi.org/10.1029/ 2018PA003481, 2019.

O’Neill, C. M., Hogg, A. M., Ellwood, M. J., Eggins, S. M., and Opdyke, B. N.: The [simple carbon project] model v1.0, Geoscientific Model Development, 12, 1541-1572, https://doi.org/10.5194/gmd-12-1541-2019, https://gmd.copernicus.org/articles/12/1541/2019/, 2019.

Petit, J. R., Jouzel, J., Raynaud, D., Barkov, N. I., Barnola, J.-M., Basile, I., Bender, M., Chappellaz, J., Davis, M., Delaygue, G., Delmotte, M., Kotlyakov, V. M., Legrand, M., Lipenkov, V. Y., Lorius, C., PÉpin, L., Ritz, C., Saltzman, E., and Stievenard, M.: Climate and atmospheric history of the past 420,000 years from the Vostok ice core, Antarctica, Nature, 399, 429-436, https://doi.org/10.1038/20859, https://doi.org/10.1038/20859, 1999.

Ridgwell, A., Hargreaves, J. C., Edwards, N. R., Annan, J. D., Lenton, T. M., Marsh, R., Yool, A., and Watson, A.: Marine geochemical data assimilation in an efficient Earth System Model of global biogeochemical cycling, Biogeosciences, 4, 87-104, https://doi.org/10.5194/bg4-87-2007, https://bg.copernicus.org/articles/4/87/2007/, 2007.

Rothman, D. H.: Earth's carbon cycle: A mathematical perspective, Bulletin of the American Mathematical Society, 52, 47-64, https://doi.org/https://doi.org/10.1090/S0273-0979-2014-01471-5, https://www.ams.org/journals/bull/2015-52-01/ S0273-0979-2014-01471-5/, 2015.

Rothman, D. H.: Characteristic disruptions of an excitable carbon cycle, Proceedings of the National Academy of Sciences, 116,14813 LP - 14 822, https://doi.org/10.1073/pnas.1905164116, http://www.pnas.org/content/116/30/14813.abstract, 2019.

Sabine, C. L., Feely, R. A., Gruber, N., Key, R. M., Lee, K., Bullister, J. L., Wanninkhof, R., Wong, C. S., Wallace, D. W. R., Tilbrook, B., Millero, F. J., Peng, T.-H., Kozyr, A., Ono, T., and Rios, A. F.: The Oceanic Sink for Anthropogenic CO2, Science, 305, 367-371, https://doi.org/10.1126/science.1097403, https://science.sciencemag.org/content/305/5682/367, 2004.

Sarmiento, J. L. . and Gruber, N. .: Ocean biogeochemical dynamics, Princeton University Press, Princeton SE - xii, 503 pages, 8 pages of plates : illustrations (some color), maps (some color) ; $29 \mathrm{~cm}, 2006$.

Schmittner, A., Brook, E. J., and Ahn, J.: Impact of the ocean's Overturning circulation on atmospheric CO2, https://doi.org/https://doi.org/10.1029/173GM20, https://doi.org/10.1029/173GM20, 2007.

Talley, L. D.: Closure of the Global Overturning Circulation Through the Indian, Pacific, and Southern Oceans: Schematics and Transports, Oceanography, 26, 80-97, https://doi.org/https://doi.org/10.5670/oceanog.2013.07, https://doi.org/10.5670/oceanog.2013.07, 2013.

515 Toggweiler, J. R. and Russell, J.: Ocean circulation in a warming climate, Nature, 451, 286-288, https://doi.org/10.1038/nature06590, https: //doi.org/10.1038/nature06590, 2008. 
https://doi.org/10.5194/esd-2021-42

Preprint. Discussion started: 8 July 2021

(c) Author(s) 2021. CC BY 4.0 License.

(c) (i)

Vellinga, M. and Wood, R. A.: Global Climatic Impacts of a Collapse of the Atlantic Thermohaline Circulation, Climatic Change, 54, 251-267, https://doi.org/10.1023/A:1016168827653, https://doi.org/10.1023/A:1016168827653, 2002.

Wanninkhof, R.: Relationship between wind speed and gas exchange over the ocean, Journal of Geophysical Research: Oceans, 97, 73737382, https://doi.org/https://doi.org/10.1029/92JC00188, https://doi.org/10.1029/92JC00188, 1992.

Weijer, W., Cheng, W., Drijfhout, S. S., Fedorov, A. V., Hu, A., Jackson, L. C., Liu, W., McDonagh, E. L., Mecking, J. V., and Zhang, J.: Stability of the Atlantic Meridional Overturning Circulation: A Review and Synthesis, Journal of Geophysical Research: Oceans, 124, 5336-5375, https://doi.org/https://doi.org/10.1029/2019JC015083, https://doi.org/10.1029/2019JC015083, 2019.

Weijer, W., Cheng, W., Garuba, O. A., Hu, A., and Nadiga, B. T.: CMIP6 Models Predict Significant 21st Century Decline of the Atlantic Meridional Overturning Circulation, Geophysical Research Letters, 47, e2019GL086075, https://doi.org/https://doi.org/10.1029/2019GL086075, https://doi.org/10.1029/2019GL086075, 2020.

Weiss, R. F.: Carbon dioxide in water and seawater: the solubility of a non-ideal gas, Marine Chemistry, 2, 203-215, https://doi.org/https://doi.org/10.1016/0304-4203(74)90015-2, https://www.sciencedirect.com/science/article/pii/0304420374900152, 1974.

530 Williams, R. G. and Follows, M. J.: Ocean Dynamics and the Carbon Cycle: Principles and Mechanisms, Cambridge University Press, Cambridge, https://doi.org/DOI: 10.1017/CBO9780511977817, https://www.cambridge.org/core/books/ ocean-dynamics-and-the-carbon-cycle/31EF28FEF48A172FF746B3E654F9455A, 2011.

Zeebe, R. E.: LOSCAR: Long-term Ocean-atmosphere-Sediment CArbon cycle Reservoir Model v2.0.4, Geoscientific Model Development, 5, 149-166, https://doi.org/10.5194/gmd-5-149-2012, https://gmd.copernicus.org/articles/5/149/2012/, 2012.

535 Zelinka, M. D., Myers, T. A., McCoy, D. T., Po-Chedley, S., Caldwell, P. M., Ceppi, P., Klein, S. A., and Taylor, K. E.: Causes of Higher Climate Sensitivity in CMIP6 Models, Geophysical Research Letters, 47, e2019GL085782, https://doi.org/https://doi.org/10.1029/2019GL085782, https://doi.org/10.1029/2019GL085782, 2020.

Zhu, J., Liu, Z., Zhang, J., and Liu, W.: AMOC response to global warming: dependence on the background climate and response timescale, Climate Dynamics, 44, 3449-3468, https://doi.org/10.1007/s00382-014-2165-x, https://doi.org/10.1007/s00382-014-2165-x, 2015. 